\title{
UNURREY
}

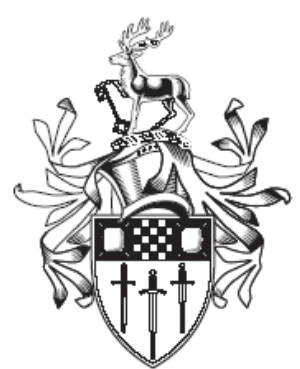

Discussion Papers in Economics

\section{MEASURING FINANCIAL CONTAGION WITH EXTREME COEXCEEDANCES}

By

Apostolos Thomadakis

(University of Surrey)

DP $11 / 12$

Department of Economics

University of Surrey

Guildford

Surrey GU2 7XH, UK

Telephone +44 (0)1483 689380

Facsimile +44 (0)1483 689548

Web www.econ.surrey.ac.uk

ISSN: $1749-5075$ 


\title{
MEASURING FINANCIAL CONTAGION WITH EXTREME COEXCEEDANCES*
}

\author{
APOSTOLOS THOMADAKIS ${ }^{\dagger}$
}

University of Surrey

August 16, 2012

\begin{abstract}
This paper tests for contagion firstly, within the Euro Area (EA thereafter), and secondly from the US to the EA. Using "coexceedances" - the joint occurrences of extreme negative and positive returns in different countries in a given day - I define contagion within regions as the fraction of the coexceedances that cannot be explained by fundamentals (covariates). On the other hand, contagion across regions can be defined as the fraction of the coexceedance events in the EA that is left unexplained by its own covariates but that is explained by the exceedances from the US. Having applied a multinomial logistic regression model to daily returns on 14 European stock markets for the period 2004-2012, I can provide the following summary of the results. Firstly, I found evidence of contagion within the EA. Especially, the EA 10 year government bond yield and the EUR/USD exchange rate fail to adequately explain the probability of coexceedances in Europe. Therefore, these variables are important determinants of regional crashes. In addition, I have observed that negative movements in stock prices follow continuation patterns - coexceedances cluster across time. Secondly, there is no statistically significant evidence of contagion from the US to the EA, in the sense that US exceedances fail to explain high probabilities of coexceedances in the EA. This result holds under a large battery of robustness checks. I would rather interpret this as a normal interdependence between the two markets.

JEL classification: C25, E44, F36, G15
\end{abstract}

Keywords: Coexceedances, Contagion, Extreme Returns, Multinomial Logistic Regression

*Earlier versions of this paper have been presented at the $17^{\text {th }}$ Spring Meeting of Young Economist (SMYE), Mannheim, April 26-28, 2012; the $18^{\text {th }}$ International Conference on Computing in Economics and Finance, Prague, June 27-29, 2012 and the $29^{\text {th }}$ GdRE Annual International Symposium of Money, Banking and Finance, Nantes, June 28-29, 2012. Comments by participants at these events are gratefully acknowledged, especially those of discussants Elisabeth Wieland and Francesca Rinaldi at the SMYE and GdRE conferences respectively.

${ }^{\dagger}$ Correspondence to: School of Economics, Faculty of Business, Economics and Law, University of Surrey, Guildford, Surrey, GU2 7XH, United Kingdom. Email: A.Thomadakis@surrey.ac.uk 


\section{Contents}

1 Introduction 3

2 Model $\quad 7$

3 Data 9

4 Empirical framework and results $\quad 14$

$4.1 \quad$ Base model . . . . . . . . . . . . . . . . . . . . . . . . . . . . 14

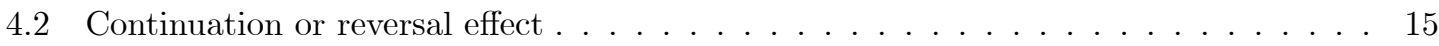

4.3 Contagion within Euro Area . . . . . . . . . . . . . . . . . 16

4.4 Contagion from the US to the Euro Area $\ldots \ldots \ldots \ldots \ldots$

5 Robustness checks $\quad 19$

6 Conclusion 21

$\begin{array}{ll}\text { References } & 23\end{array}$

$\begin{array}{lr}\text { Appendix A } & 26\end{array}$

Appendix B 33

$\begin{array}{ll}\text { Appendix C } & 46\end{array}$ 


\section{Introduction}

The aim of this paper is to shed light to whether contagion exists or not within the Europe region, but also to detect, if that is possible, contagion effects from the US to the Euro Area. In other words, I am interested in making a contribution to a better understanding of the degree to which European markets have become interconnected and to the level on which the sub-prime crisis which started in the US, spread across borders and increased or decreased the likelihood of a crisis in the EA.

The understanding of the relationship between financial markets signifies a key question, which has spawned a number of studies. Both investors and policymakers are particularly keen to understand the mechanisms that link markets - in order to be able firstly to assess the benefits of portfolio diversification and secondly to maintain financial stability. This motivation is even greater in times of financial crisis, where the vital question is whether and how the crisis propagates from one market or country to another. Therefore, we need to know whether or not we can classify this diffusion of shocks from one country to another as contagion.

In the existing literature, there is widespread disagreement on what is contagion. For some economists, contagion exists only when a crisis starts from one economy and spreads to another, when the two economies are located in separate geographic regions, with different structures and weak cross-market linkages. Others prefer to use the term shift-contagion (Forbes and Rigobon, 2002). According to this term, contagion is the significant increase in cross-market linkages after a shock to one country or to a group of countries. However, when the degree of comovement between two countries is high prior to the shock and continues being high even after the crisis, this does not constitute contagion. We would rather describe this as a normal interdependence between the countries under research.

In the present paper, I will use the term "pure contagion", which means that a crisis might trigger additional crises elsewhere for reasons unexplained by fundamentals. In other words, a crisis in one market/country increases the likelihood of a crisis in another market/country over and above what would be implied by the interdependence that prevails between these markets/countries in non-crises times. This contrasts with many studies, which have involved simply comparing comovements before and during the crisis.

For the detection and identification of contagion in financial markets, many different approaches 
have been proposed. On the one hand, we find studies that attempt to measure the effect of a shock in one country on another country: i) leading indicator approaches (Kaminsky et al., 1998; Berg and Pattillo, 1999) and ii) probit/logit models (Eichengreen et al., 1996; Forbes, 2001; Bae et al., 2003; Christiansen and Ranaldo, 2009). In another strand of literature, we find studies that test discontinuities in the data-generating process: i) Markov-Switching models (Jeanne and Masson, 2000; Fratzscher, 2003) and ii) tests of structural breaks in the correlation coefficients (Corsetti et al., 2001; Forbes and Rigobon, 2002; Rigobon, 2003).

There is a vast number of studies, by King and Wadhwani (1990), Boyer et al. (1999), Loretan and English (2000) and Forbes and Rigobon (2002) amongst others, which have been conducting tests on significant changes in correlations between asset returns during tranquil and turmoil periods. There are mainly two reasons why pure correlation-based tests are inappropriate and invalid for contagion testing. Firstly, correlation-based tests are a positive function of volatility. Given the fact that during crises financial returns exhibit high volatility, a correlation test is biased upwards resulting in spurious contagion. Secondly, correlation coefficient is a linear measure which gives equal weight to negative and positive return. This contradicts with the definition of contagion as a measure which captures non-linear changes in financial markets. For these reasons, this study will concentrate on the first strand of research and especially on multinomial logit models.

Along this line, there are studies which focus on extreme events in different financial markets and on the probability of observing large returns across different markets given than in one market or country there already exist extreme tail events. Bae et al. (2003) used a binomial logistic regression model for the extreme stock events in the US and the EA for the period 1995-2000. Their model, which is estimated separately for negative and positive tail events, shows evidence that interest rates, opposite to stock market volatility and exchange rate, might be a source of contagion within the EA. Additionally, they conclude that there is contagion phenomenon from the US to the EA, as extreme returns happening in the US have a significantly large positive impact to shocks occurring in EA. Chan-Lau et al. (2004) apply the extreme value theory (EVT) in order to quantify the joint behaviour of extremal realisations (coexceedances) of financial returns across emerging markets in Latin America and Asia. The same approach, EVT, was followed by Hartmann et al. (2004) who directly measured the expected number of stock and bond market crashes, for the G5 countries, conditional on the event that at least one market crashes. 
The quantile regression model of Koenker and Bassett (1978) was applied by Baur and Schulze (2005) in order to analyse not only the occurrence of extreme events, but also the degree of the negative joint occurrences. The authors concentrate only on Hong Kong, Thailand and Malaysia, as the source countries of the Asian crisis, testing for contagion effects from the US, Latin America, Europe and other Asian countries. The results are mixed, as in some cases they found contagion, and in others interdependence. Investigating the link between extreme events on the stock and currency markets, Cumperayot et al. (2006) applied a bivariate probit model and concluded that only for some countries (Brazil, Canada, US and Switzerland) out of a total of 26, currency depreciation does decrease the probability of a stock market decline. Groop et al. (2006), within a multinomial logistic framework using the distance to default measure, were able to examine the occurrence of large changes in this measure as describing major shocks in banks' financial condition. The results show significant evidence that cross-border contagion has increased since the introduction of euro.

Fazio (2007), based on bivariate probit models, tried to identify contagion currency crises using exchange market pressure indices between country pairs for a sample of 14 emerging economies. By distinguishing between the transmission of shocks due to macroeconomic interdependence and contagion due to herding, he found evidence of contagion for few cases only and especially between countries belonging to the same region. In another paper, Christiansen and Ranaldo (2009), used the multinomial logit model in order to analyse the financial integration between the old European Union (EU) countries and the new EU member states and how this integration changed or not after the EU enlargement in 2004. Results show that for both old and new EU countries, the currency and interest rate play an important role in the transmission of shocks. Markwat et al. (2009) define three categories of crashes: local, regional, and global. Following an ordered logit model the authors conclude that: first, there is significant evidence that less severe crashes tend to be followed by more severe crashes; and second, the stock, bond and currency markets are important determinants of the probabilities of the different crash events.

In this paper, I propose to investigate the contagion effect - if any - within the EA as well as from the US to the EA, by examining how often extreme (negative and positive) returns on different markets occur simultaneously. Using a negative-positive coexceedance variable that counts the number of large negative-positive returns on a given day across countries, I provide an answer to the question: "How likely is it for a market or a country to have large returns on a particular day, 
given that some other market or country have large returns on that day or the preceding day?". Borrowing the definition of contagion from Bae et al. (2003), I define contagion within regions as the fraction of exceedance events that is not explained by the explanatory variables (such as bond yield, interest rate and exchange rate). On the other hand, contagion across regions can be defined as the fraction of the exceedance events in a particular region that is left unexplained by its own covariates but that is explained by the exceedances from another region.

In addition, within this particular framework, I am able to allow for both types of transmission mechanisms, contagion and interdependence. When two countries are closely linked to each other through economic fundamentals, trade links, political links or geographical position, among others, then the spillover of shock from the one to another will be the result of the normal dependence between the two markets. Consequently, we can say that interdependence refers to the dependence that exists both in tranquil or turbulent times. On the other hand, contagion constitutes a form of dependence that does not exists in tranquil times but only occurs in times when large or extreme shocks to financial markets occur. According to Dornbusch et al. (2000), contagion cannot be linked to observed changes in macroeconomics or other fundamentals and is solely the result of the behaviour of investors, financial agents or other irrational phenomena, such as financial panic, herd behaviour or loss of confidence. As described earlier, in this paper I define contagion as the dependence that still exists after correcting for interdependence (fundamentals).

Using a multivariate logistic regression model, I will examine which covariates-factors are associated with the coexceedances count variables. The main results of this paper can be summarised as follows. First, I found that the EA 10 year government bond yield and the EUR/USD are important determinants of regional crash. These covariates fail to explain extreme stock returns happening in the EA, and therefore there is evidence of contagion from these markets towards the stock market. What is more, there is evidence in favour of the continuation effect. This means that extreme negative returns do not occur abruptly, but rather evolve out of prior negative extreme returns. The probability of observing a crisis tomorrow in the EA, in the sense of joint occurrence of extreme negative returns in four or more countries simultaneously, increases when regional crash occurs today. Second, the results show that there is no evidence of contagion from the US to the EA. The probability of extreme returns in the EA is not statistically significant related to extreme returns happening in the US. According to the definition of contagion mentioned above, this con- 
stitutes that there is no contagion phenomenon from the US towards the EA. This finding is also supported by the fact that the coefficients of the US stock market volatility are negatively statistcially significant at $1 \%$ significance level. I will rather interpret this as normal interdependence between the two markets.

The paper is structured as follows. Section 2 describes the multinomial logit model, while Section 3 presents the data. In Section 4, I set-up the different models to be tested and present the empirical results, while Section 5 describes all the robustness checks that I performed. Finally, Section 6 presents the conclusions, as well as areas of future research.

\section{Model}

The paper follows the approach employed by Bae et al. (2003) and Christiansen and Ranaldo (2009), and models extreme returns as a discrete choice among a set of alternatives. The main goal is to model the number of extreme negative and positive returns within the EA occurring in more than one countries simultaneously, as a function of some covariates, and to express the results in terms of probabilities for choice of different events. McFadden (1974) proposed a modification of the logistic regression model and called it a discrete choice model or, as frequently referred, the multinomial, polychotomous logistic regression.

In this model, the dependent variable is an indicator of a discrete choice. At this point, I need to introduce the exceedance and coexceedance terms. An exceedance can be defined as the occurrence of an extreme negative (positive) return which lies below (above) a given threshold value of the return distribution in one country. Similarly, coexceedance refers to the occurrence of extreme negative and positive returns in different countries at the same day. In line with the majority of the studies examining extreme tail events, I choose the tail probability $5 \%$ for the definition of extremes. This decision can be defended given the large sample of daily observations, implying that the empirical distribution will contain a large number of observations in the tails. This will ensure that sufficient number of observations will be available to estimate the logit model and the conditional probabilities. ${ }^{1}$ After all, I distinguish between the following events: no extreme return for a given day; only one country with an extreme return (exceedance); two countries with an

\footnotetext{
${ }^{1}$ As a robustness check and in order to investigate the sensitivity of my results to the $5 \%$ quantile, in Section 5 , I will estimate all the models using different exceedances definitions.
} 
extreme return (coexceedance); three countries with an extreme return (coexceedance); and four or more countries with an extreme event (coexceedance).

The basic idea is to analyse each of the exceedance-coexceedance events in the general framework of probabilities model:

$\operatorname{Pr}($ event $j$ occurs $)=\operatorname{Pr}\left(Y_{i}=j\right)=F($ covariates-explanatory variables $)$ for $j=1, \ldots, m$,

where the function $F($.$) on the right-hand side will be devised using a logistic cumulative distri-$ bution. In addition, the set of covariates reflects the impact of changes in "relevant effects" (the independent variables) on the probability of observing a negative or a positive extreme return. In general form, by assuming that the probability associated with an event $j$ of $m$ possible events is given by $\operatorname{Pr}\left(Y_{i}=j\right)$, then the multinomial distribution can be defined as:

$$
\operatorname{Pr}\left(Y_{i}=j\right)=\frac{\exp \left(x \beta_{j}\right)}{1+\sum_{k=1}^{m} \exp \left(x \beta_{k}\right)} \text { for } j=0,1, \ldots, m
$$

where $x$ is a vector of explanatory variables (including a constant) and $\beta_{j}$ is a vector of coefficients for categories $j$ to $m$. In order to remove the indeterminacy associated with the model, the event $Y=0$ (zero exceedances) will be the base-benchmark model. Therefore, all coefficients are estimated in relation to this base:

$$
\operatorname{Pr}\left(Y_{0}\right)=\frac{1}{1+\sum_{k=1}^{m} \exp \left(x \beta_{k}\right)}
$$

The model is estimated using the log-likelihood function:

$$
L L=\sum_{i=1}^{N} \sum_{j=1}^{m} I_{i j} \ln P_{i j},
$$

where $N$ is the number of observations, $I_{i j}$ is an indicator variable that equals one if the $i^{t h}$ observation falls in $j^{\text {th }}$ event and zero otherwise. If the model contains no covariates, but only a constant term, then the restricted log-likelihood is given by:

$$
L L_{r}=\sum_{j=1}^{m} n_{j} \ln \left(\frac{n_{j}}{n}\right)=\sum_{j=1}^{m} n_{j} \ln p_{j}
$$


where $p_{j}$ is the sample proportion of observations that make choice $j$. In order to measure how well the model fits the data, as well as the percentage of the variation in the dependent variable that is explained by the estimated model, I am using the McFadden's pseudo- $R^{2}$ goodness-of-fit:

$$
\text { pseudo }-R^{2}=1-\left(\frac{L L_{u}}{L L_{r}}\right),
$$

where $L L_{u}$ is the value of the log-likelihood function at the estimated parameters (unrestricted model), and $L L_{r}$ is its value when all the parameters - except constant - are set equal to zero (base model). Additionally, I use the $\chi^{2}$ Wald test in order to test the hypothesis that coefficients of the explanatory variables are zero.

Finally, for the interpretation of the coefficient values, I compute the marginal effects of the explanatory variables on the probabilities. Following Greene (2008):

$$
\frac{\partial P_{i j}}{\partial x_{i}}=P_{i j}\left[\beta_{j}-\sum_{k=0}^{m} P_{i k} \beta_{k}\right]
$$

which measures the marginal changes in the response probabilities for any given unit change in the independent covariate. All the models are estimated using PCGive in OxMetrics.

\section{Data}

While the majority of studies calculate exceedances in terms of the sample period (unconditional) returns, in this paper I will use the standardised residuals of a GARCH model, and based on them I will construct the coexceedances variables. The reason for doing this lies in my aim to control the fact that more exceedances happen in periods of higher conditional volatility. Otherwise, my results may be influenced by the effects of time-varying volatility. As Bae et al. (2003) commented, with this method the probability of observation of an exceedance is always the same.

For the purposes of this study, I use daily (close-to-close) ${ }^{2}$ data of industrial stock market return index for 14 European countries (part of the European Monetary Union) and the United States for the period from January 1, 2004 to July 11, 2012 - a total of 2224 observations. ${ }^{3}$ All the data cited

\footnotetext{
${ }^{2} \mathrm{I}$ am aware of the potential bias that is introduced by using this type of returns since trading hours are not synchronous.

${ }^{3}$ The countries are: Austria (AUS), Belgium (BEL), Cyprus (CYP), Finland (FIN), France (FRA), Germany (GER), Greece (GRE), Ireland (IRE), Italy (ITA), Malta (MAL), Netherlands (NET), Portugal (POR), Slovenia
} 
in this paper are obtained from Datastream and are expressed in euros - from the perspective of an unhedged European investor. I decided to use daily data instead of low-frequency data, because I treat contagion as a relatively short-lived phenomenon, whose extremes would not be captured by monthly or quarterly data. Return series are calculated by applying the formula, $r_{t}=\ln p_{t}-\ln p_{t-1}$, where $p_{t}$ is the stock price in time $t$. Table 1 gives details on the exact sources employed on this paper and on their mnemonics, while Table 2 provides summary statistics for the industrial stock market index returns for all the countries under consideration. Figure 1 and 2 plot the industrial stock market return index and the return series, respectively, over the entire sample period.

Mean stock returns in annualised terms vary from $-17.33 \%$ in the case of Slovenia to $14.51 \%$ for Finland, while volatilities - defined as the standard deviation of returns - vary between $17.18 \%$ for Malta to $37.28 \%$ for Ireland. ${ }^{4}$ What is more, all the series - except for Cyprus and Ireland are characterised by negative skewness, implying that the distributions have a long left tail, and the mass of the distribution is concentrated on the right. This suggests that crashes occurs more often than booms. Opposite to that, the Cypriot and Irish markets have large positive skewness, indicating that large positive returns tend to occur more often than large negative returns in these countries. Furthermore, all the series display large positive kurtosis coefficients well above the Gaussian benchmark value of three for the normal distribution. Kurtosis is between 6.0327 (Italy) and 19.0235 (Portugal), a range that is inconsistent with the assumption of normality. ${ }^{5}$

The considerably large values of excess kurtosis are reflected in the high values of JB statistics, which lead us to the rejection of the null hypothesis of normal distribution at the $1 \%$ significance level. Finally, this table also shows the Ljung-Box (LB) Q statistic for fifth order serial correlation in levels and squares of returns, since there are five trading days in a week. The Q statistic points out that for five out of twelve countries (Cyprus, Ireland, Italy, Malta and Italy) there is no strong evidence for serial correlation in levels, while the squared returns are strongly correlated, which suggests temporal variation in second moments - evidence of time-varying volatility (heteroskedasticity).

Table 3 illustrates unconditional correlations among the countries for the full sample period. One can observe that all values (except those involving Malta) are positive, thereby reflecting (SLO) and Spain (SPA).

${ }^{4}$ The annualised values are computed using 252 trading days per year.

${ }^{5}$ The fact that for Portugal and Ireland the kurtosis is two to three times larger than for any other country, indicates that in these two markets there are more events at the tails (extreme events). 
regional and economic relationships among countries. Correlation is taking its largest value between France and Germany (0.86). Given the well-known time variability of correlations, these sample correlations may be biased and misleading. All the series were tested on whether they are stationary or not. Results from the Augmented Dickey Fuller (ADF) test are reported in Table 2.

In Table $4, \mathrm{I}$ report the number of negative $\left(R N_{t}\right)$ and positive $\left(R P_{t}\right)$ exceedances and coexceedances for the 14 European markets. The total 2224 days in my sample are divided into five categories: those for which there are no exceedances in any country (1536 such days for negative extreme events); only one exceedance (413 for negative extreme returns); two; three; and four or more coexceedances. I also identify which countries participate in those events and how often. The columns labeled " $5^{t h}$ quantile", " $95^{\text {th }}$ quantile", "Mean" and "Volatility" report the $5 \%$ and 95\% quantile of the standardised residuals together with the mean value and the volatility. The lowest mean for negative extreme returns belongs to Austria, Malta and Spain indicating that in these countries the extreme returns introduce more risk. Furthermore, the high volatility for Malta, Greece and Portugal implies that negative returns vary more in these countries than in the other countries. Looking at the top-tail events, Cyprus, Ireland and Malta are experiencing the higher values of mean and volatility, a result which is expected if one takes closer look at the descriptive statistic of the series.

What is more, Table 5 documents some stylised facts on the dynamic properties of the different types of exceedances events. Following Markwar et al. (2009), I use the "exceedance-coexceedance transition matrix", in order to understand how the exceedances evolve and to assess whether modelling extreme returns using coexceedances is appropriate or not. each $i j$ th entry of this transition matrix represents the probability of observing the state in column $j$, given that on the previous day the state in row $i$ occurred. Several interesting results emerge from this matrix. Panel A shows how the probabilities of observing a bottom-tail coexceedance (no matter how many countries are involved) on the next day increases from 0.22 when no exceedance occurs today via $0.25,0.43$ and 0.43 to 0.51 when four or more exceedances occur today. For both three and four or more coexceedances I find probabilities of occurrence, conditional on the occurrence of a coexceedance on the previous day. The probabilities of observing extreme negative returns in four or more countries, for example, increase from 0.04 when no exceedance occurred on the previous day, via 0.13 to 0.17 following the occurrence of a two- or three-countries coexceedances, respectively. 
The same pattern is also true for extreme positive returns. Furthermore, I found increasing probabilities of occurrence for three and four or more exceedances, conditional on the occurrence of an exceedance on the previous day. To be more precise, the probabilities of observing a joint occurrence of exceedances increase from 0.04 when there are no extreme returns in any country on the previous day, to 0.06 when there is only one exceedance, to 0.13 following the occurrence of four or more countries in the bottom tail. These results indicate that extreme returns do not happen abruptly but rather evolve out of prior extreme returns, which suggests that modelling extreme returns as a exceedance/coexceedance effect makes sense.

Panel B of Table 5 shows the transition probabilities using the definition of exceedances based on standardised residuals. As I mentioned earlier, my aim is to examine whether the results of exceedances dynamics are driven by the volatility effect which is observed during times of extreme downturns, as Boyer et al. (1999), Loretan and English (2000) and Forbes and Rigobon (2002) argued. After controlling for volatility, I found lower probabilities for three and four or more exceedances when an exceedance occurred on the previous day. For instance, the probability of observing extreme negative return in three countries today and a joint occurrence (four or more countries) tomorrow decreases from 0.17 to 0.05 . The probability that a joint occurrence continues is 0.09 , compared to the 0.14 for sample returns. Therefore, I conclude that there are volatility dependences in the dynamic patterns of coexceedances - especially concerning the more severe events - that one should take into account when testing for contagion using extreme return measures.

Additionally, and in order to discriminate the impact of contagion from the effect of fundamentals, I use a large set of explanatory variables. In my choice of variables, I follow the existing literature, and select to a large extent the same variables as Bae et al. (2003), Markwat et al. (2009) and Christiansen and Ranaldo (2009). Importantly, the frequency of all the explanatory variables does correspond with the frequency of my observations. First, since I used industrial stock market return index to compute the exceedances, I decide to add in my model the financial stock market return index. By doing so I will be able to see how the two sectors are linked, as well as the dynamics that explain their behaviour. Additionally, to investigate whether shocks in the bond market lead to increased crash likelihood, I include daily yields on long maturity bonds - 10 year government bond yields. I expect a negative effect of bond yields on probabilities of coexceedances. A fall in their yields - or an increase in their prices - may point at an increase in 
the probability of four or more countries coexceedances.

I also include the 3-month interbank interest rate, EURIBOR, which is the reference rate at which Euro interbank deposits are being offered within the European Monetary Union zone by one bank to another, reflects the average cost of funding of banks in the interbank market for a specific maturity. On average, stock market returns are negatively correlated with interest rates, since the latter imply higher costs of capital. So, I expect that higher interest rates will increase the contagion probability. For the currency market I use the exchange rate of the Euro against the US Dollar. If Euro depreciates against the US Dollar, extreme returns are more likely to happen. This is true if one considers that a depreciation will lead to a lower value of the stock index. Figure 3 illustrates the four explanatory variables.

Finally, I will also use two covariates related to the US. These are: i) the exceedance variable counting the number of days with extreme negative (below the 5\%) and positive (above the 95\%) percentile of the standardised residuals of the industrial stock market distribution; and ii) the volatility of the industrial stock market. Volatility is computed as the squared root of the conditional volatility of the $\mathrm{AR}(1)-\mathrm{GARCH}(1,1)$, following a common practice in the existing literature. To be more precise, I estimate the model: $U S I_{t}=c_{0}+c_{1} U S I_{t-1}+\varepsilon_{t}$ where $\varepsilon_{t} \sim N\left(0, \sigma_{t}^{2}\right)$ and the variance follows a $\operatorname{GARCH}(1,1)$ process: $\sigma_{t}^{2}=c_{2}+c_{3} \sigma_{t-1}^{2}+c_{4} \varepsilon_{t-1}^{2}$.

- $R N_{t-1}$ and $R P_{t-1}$ : lagged values of negative and positive co-exceedances variables.

- EAF: return on financial stock market index for the Europe (EMU only).

- EA10Y: return on 10 year government bond yield for the Europe (EMU only).

- EURIBOR3M: return on 3 month Euro Interbank Offered Rate.

- $E U R / U S D$ : return on currency exchange rate.

- $U S R N$ and $U S R P$ : negative and positive exceedance variable for the US.

- $U S R N_{t-1}$ and $U S R P_{t-1}$ : lagged values of negative and positive exceedance variable for the US.

- $U S I$ and $U S I_{t-1}$ : return on industrial stock market index for US and its lagged value. 
- USIvol and USIvol ${ }_{t-1}$ : volatility of return on industrial stock market index for the US and the lagged value.

\section{Empirical framework and results}

In this section, I perform four sets of estimations - the base model, the "continuation or reversal effect", the "contagion within the EA" model, and the "contagion from the US to EA" model.

\subsection{Base model}

Model 1 of tables 6 and 7 reports estimates of probabilities of coexceedances for bottom- and toptail events for the EA. Equation 1 can be written as a function of the explanatory variables. So, the probability of being in category $i$ is given by:

$$
\operatorname{Pr}\left(Y_{i}=j\right)=\operatorname{function}\left(x \beta_{j}^{\prime}\right) \text { for } j=1, \ldots, m
$$

This is the base model against which I compare all the other models. What I found is that there is a probability of $69.06 \%$ that none of the 14 European countries of my sample has a negative extreme return, while for the top-tail events this probability reaches $64.52 \%$. The probability that one country has an extreme negative return is $18.57 \%$ ( $21.71 \%$ for top-tail events), while joint occurrence of extreme returns in four-and-more countries is $5.44 \%$ (4.94\% for top-tail events). These probabilities are associated with the coefficients $\beta_{01}$ and $\beta_{04}$ respectively; and can be easily computed from Equation 2. For example:

$$
\operatorname{Pr}(Y=1)=\frac{\exp \left(\beta_{01}\right)}{1+\sum_{j=1}^{4} \exp \left(\beta_{0 j}\right)}=\frac{\exp \left(\beta_{01}\right)}{1+\left[\exp \left(\beta_{01}\right)+\exp \left(\beta_{02}\right)+\exp \left(\beta_{03}\right)+\exp \left(\beta_{04}\right)\right]}
$$

Since Model 1 does not include explanatory variables, but only the constant term, these probabilities can also arise from Table 4, which presents analytically the number of negative and positive exceedances and coexceedances for each country. 


\subsection{Continuation or reversal effect}

In this section, I am interested to explore if extreme returns - negative and positive exceedances

- in stock prices are followed by subsequent movements in the opposite (reversal) or in the same direction (continuation). Existing literature has identified both patterns. DeBondt and Thaler (1985), influenced by experiments in psychology showing that dramatic and unexpected news make people overreact, tried to investigate whether such behaviour affects stock prices. They found a reversal pattern in long-term (3- to 5-year) returns, as well as that stocks with low past returns tend to have higher future returns. Most recent papers by Jegadeesh (1990) and Lehmann (1990) provide evidence of shorter-term (3- to 12-month) return reversals. These studies show that investors who select their stocks based on the previous week or month returns generate significant abnormal returns.

In contrast, Jegadeesh and Titman (1993) and Fama and French (1996) have found that shortterm returns tend to continue (continuation pattern); stocks with higher returns in the previous twelve months tend to have higher future returns. This finding is also supported by Christiansen and Ranaldo (2009), who have argued that the number of extreme negative returns today is positively related to the number of extreme negative return yesterday.

Model 2 of tables 6 and 7 has one explanatory variable, the lagged value of the negative/positive coexceedances $\left(R N_{t-1} / R P_{t-1}\right)$. Equation 1 now becomes:

$$
\operatorname{Pr}\left(Y_{i}=j\right)=\operatorname{function}\left(\beta_{0 j}+\beta_{1 j} R N_{t-1}\right) \text { for } j=1, \ldots, m \text {. }
$$

The first column of each model shows the parameter estimates and their significance level, while the second column presents the impact of each covariate on the probability of exceedances. The third column reports the joint significance level of each explanatory variable $\left(\beta_{j 1}=\beta_{j 2}=\beta_{j 3}=\beta_{j 4}=0\right)$. As one observes from those tables, only for the bottom-tail events all (except for one) the coefficients are significant and positive, indicating that the more extreme negative returns we have yesterday, the more likely it is to have extreme negative returns today. In other words, there is significant evidence for the presence of a continuation effect. Extreme negative returns follow a domino effect. This result is particularly noteworthy given the fact that I have taken into account volatility, since I computed coexceedances using the standardised residuals from a $\operatorname{GARCH}(1,1)$ model. We know 
by definition that extreme negative returns are more likely to occur in times of high volatility.

Moreover, the $\Delta p r o b$, which expresses the marginal probability of exceedances with respect to the lagged value of this covariate, indicates that an increase in negative returns yesterday increases the probability of all exceedances, but the effect decreases as we move to higher number of joint occurrences. A similar interpretation can be applied to the positive coexceedances, even though the lagged variable is of no importance, as it is only significant at $10 \%$ level.

\subsection{Contagion within Euro Area}

Are the coexceedances related to different asset type returns? In Model 3, the explanatory variables on top of the past values of the coexceedances are: the EA financial stock market index returns; the aggregate 10-year government bond for the Euro Area; the short-term (3 month) EURIBOR interest rate; and the currency exchange rate between Euro and US Dollar. By adding these covariates, I am interested to see first, what is the relationship between the financial and industrial stock market; second, the effect of monetary policy decisions, as adopted by international authorities and policymakers,; and third, the impact that credit crunch had on the credit and liquidity risk perception of the market. The model has the form:

$$
\begin{gathered}
\operatorname{Pr}\left(Y_{i}=j\right)=\text { function }\left(\beta_{0 j}+\beta_{1 j} R N_{t-1}+\beta_{2 j} E A F+\beta_{3 j} E A 10 Y+\right. \\
\left.+\beta_{4 j} E U R I B O R 3 M+\beta_{5 j} E U R / U S D\right) \text { for } j=1, \ldots, m .
\end{gathered}
$$

For both negative and positive coexceedances (Model 3 of tables 6 and 7), only the financial stock market has a strong significant effect, with the coefficients to have the expected sign. In particular, the likelihood of observing negative coexceedances is negatively related to stock returns. This relationship implies that the lower the stock return, the higher the probability that four or more countries will experience negative returns in a given day. Using a numerical example, looking in the marginal effect of this covariate, a $5 \%$ decrease in the returns of the financial sector increases the probability of four or more exceedances by $7.15 \%$.

To continue, I detect no significant link between the 10-year government bond yield and the $E U R / U S D$ exchange rate with the occurrence of extreme returns. Regarding the 10-year bond yield, the result is consistent with Markwat et al. (2009), even though these authors include in 
their study a bond portfolio which consists of bonds with long and short maturities. Moving now to the currency rate, my result is consistent with Christiansen and Ranaldo (2009), who also found that the relation between negative extreme return probabilities and exchange rate movements is absent. Noteworthy to say, that these authors perform their analysis separately for new and old EU countries, and conclude that for both cases currency returns fail to adequately explain either negative or positive extreme returns. What is more, Bae et al. (2009), who employed the Euro-US Dollar bilateral exchange rate and the short rate in Germany as a proxy, using a binomial logit model conclude that the coefficient on the exchange rate is positive and significant for bottom-tail events.

Finally, the likelihood of observing bottom-tail events in three and in four-or-more countries is statistically significant at $5 \%$ and $1 \%$ significance level, respectively, for the EURIBOR 3-month interest rate. The positive coefficients of the interest rate are in line with the expectations. Higher reference rate for overnight transactions in the Euro Area will significantly increase the probability of stock market extreme tail events. Additionally, the explanatory variable is significant at $1 \%$ level as indicates the Wald test for zero exclusion.

Overall, in this section I found that in neither case is 10 year government bond yield and the $E U R / U S D$ exchange rate of importance and therefore it does not provide any substantial information. In other words, they fail to explain coexceedances happen in the EA. According to the definition of contagion that I use this constitutes evidence of contagion. Adding the financial stock returns and the three interest rates to the model increases the pseudo- $R^{2}$ up to $17.02 \%$.

Figures 4 and 5 illustrate the coexceedances response curves of the EA for the bottom- and toptail events respectively. The curves show the probabilities of the different types of exceedances for different levels of explanatory variables. Varying the value of each variable form its minimum to its maximum, I compute the probabilities of observing a type of exceedance event for all observations. Those figures support the findings presented in tables 6 and 7 .

\subsection{Contagion from the US to the Euro Area}

In this section, I am interested in investigating if there is a fraction of the coexceedances in the Euro Area left unexplained by its own covariates that can be explained by exceedances and/or other US explanatory variables, and especially stock market volatility. Of interest is whether the 
United States had an extreme return that seems more helpful in predicting the number of negative or positive extreme returns in the EA. If so, I will interpret this as an evidence of contagion from the United States to the EA. I reestimate Model 3, but now I add two covariates related to exceedances $(U S R N)$ and stock market volatility (USIvol) from the US during the preceding trading session that day. ${ }^{6}$ The new model, Model 4, has the form:

$$
\begin{aligned}
& \operatorname{Pr}\left(Y_{i}=j\right)=\operatorname{function}\left(\beta_{0 j}+\beta_{1 j} R N_{t-1}+\beta_{2 j} E A F+\beta_{3 j} E A 10 Y+\beta_{4 j} E U R I B O R 3 M+\right. \\
& \left.\quad+\beta_{5 j} E U R / U S D+\beta_{6 j} U S R N_{t-1} / U S R P_{t-1}+\beta_{7 j} U_{S I v o l} I_{t-1}\right) \text { for } j=1, \ldots, m .
\end{aligned}
$$

The estimated results for the bottom and top tails are given in Table 8. The most important finding is that the regression coefficients on the number of exceedances in the US are insignificant. This means that US extreme returns do not seem to be helpful in predicting the number of negative extreme returns in the EA. Using the definition of contagion according to which: contagion from the US to the EA can be defined as the fraction of the exceedance events in the EA that is left unexplained by its own covariates but that is explained by the exceedances from the US - this does not constitute evidence of contagion. I will rather interpret this as normal interdependence between the two regions.

For the other explanatory variable, the US stock market volatility, I found that the coefficients related with extreme negative returns in three and in four or more countries are statistically significant at $1 \%$ level. This means that the higher the US volatility yesterday, the less likely it is to have extreme events on the Euro Area today; falling stock markets in the US do not propagate or diffuse shock to the EA. Furthermore, the Wald statistic indicates that we reject the null hypothesis that the volatility coefficients are equal to zero, or equally the explanatory variable $U_{S I v o l}$ t $_{-1}$ is overall significant at the $1 \%$ level of significance. Unfortunately, there is paucity of studies matching the range of covariates that I am using and the sample period of my observations. For example, Bae et al. (2003) conclude that firstly, Europe's probability of negative extreme returns is significantly affected by extreme returns in the US; and secondly that the effect of the conditional volatility from the US is strangely negative. However, for the estimation of this result the authors plagued daily data from 1996 to 2000 into a binomial logit model.

\footnotetext{
${ }^{6}$ In Section 5 I will perform the same exercise using three- and five-day lagged values.
} 
Looking to other covariates, $E A 10 Y, E U R I B O R$ and $E U R / U S D$ are all insignificant for both bottom- and top-tail events. Any relation between probabilities of extreme returns and movements in these covariates seems absent. The only exception is the coefficient of EURIBOR3M related with top-tail events in four or more countries, which is significant at $5 \%$ significance level and has a negative sign. This implies that a lower interest rate will lower the cost for borrowing money and will therefore boost the stock market. Consequently the probability of extreme positive returns will be higher. Contrary to that, and as presented by my findings in the previous section, for top-tail events the rate was insignificant and did not add any explanatory power to the model. A possible explanation could be the interconnection between the rate at which European banks lent and borrow money from each other, with the US stock market.

\section{Robustness checks}

In this section I perform several checks in order to assess the robustness of the contagion effect that I found within the EA; and interdependence between the US and the EA.

A concern with these results is that the number of exceedances in the US might not reflect its real influence upon extreme returns in Europe, since as mentioned already earlier, the two markets are open and simultaneously operate for a small fraction of time. This turns out not to be the case. I reestimated Model 4, replacing the US negative exceedances and the US industrial volatility by their values at time $t, t-3$ and $t-5 .^{7}$ The coefficients (table 9, 10 and 11) of US exceedances are still insignificant for all exceedance outcomes for both positive and negative tails, and the partial derivatives too. Contrary, the stock market volatility of the US does seem to be very helpful in predicting exceedances in Europe, as both the coefficients and the derivatives are statistically significant at $1 \%$ level.

Furthermore, in order to measure the effect of bond, interest rate and currency changes on negative and positive extreme returns simultaneously, as well as to capture possible overreaction to bad and good news, not captured by the other variables, I include three dummy indexes associated with extreme events in bond, interest rate and currency markets. While for bond and interest rate the extreme observations are those below the $5 \%$ quantile, extreme currency depreciations

\footnotetext{
${ }^{7}$ The reason for going back five days is that during crises periods investors might need time to assess the potential effect of extreme events in the market on other markets.
} 
are defined as those depreciations above the $95 \%$ quantile of the empirical distribution of currency returns. These dummy variables are included in the model with one- and five-day lag, such that the model will be predictive in nature. For bottom-tail events and only for the model with five-day lag there is some significant relation between coexceedance events in three countries and interest and exchange rate movements. The explanation power of the indicators continues to exist for positive extreme returns. Interestingly, even when I include (tables 12 and 13) or exclude (Model 6 of tables 6 and 7) these variables, the estimated coefficients for average bond, interest rate and currency changes remain insignificant. Given the fact that each extreme indicator simply subsumes all effects of the corresponding market rates (bond, interest and currency rate) on stock market returns, this implies that stock markets only react to substantial depreciations. Following Markwat et al. (2009), I interpret this finding as another form of contagion, from these markets to stock market.

Another concern with my results is whether or not the bear market period, starting on June 2007 and afterwards, may bias my findings. For that reason, I performed the same analysis splitting my sample period into two sub-periods, from January 2004 to May 2007 and from June 2007 to July 2012. Results, which are reported on tables 14, 15, 16 and 17, are similar to those reported before.

Another issue that I needed to tackle in order to render my results comparable with previous studies is the GARCH standardised residuals. I reestimated all the models, but this time I defined exceedances differently from the way I had defined them so far, as I use sample period returns (tables 18 and 19). Even though this approach does not seem to be appropriate, since I will always have an outcome where there are more exceedances in periods of higher conditional volatility, the results are somewhere in the middle. With this definition of exceedances, more coefficients are significant. For Model 3 and for bottom-tail events, I found that the probability of coexceedances is affected by the interest rate and by exchange rate shocks. If currency falls (EUR/USD rises), extreme returns are more likely. Additionally, few of the bond yield and EURIBOR rate coefficients are significant and of negative sign, which implies that negative exceedances will occur when bond yields and interest rates are low. If yield decreases by $10 \%$ the probability of three exceedances will increase by $1.7 \%$. When I examine top-tail events, the interest rate coefficients are negative and significant. In other words, the likelihood of observing positive extreme returns in more than one 
country increases when the interest rate in the region falls.

Looking at bottom-tail events of Table 19, the regression coefficients on the number of exceedances in the US are insignificant for all but three-country coexceedances. In computing the derivative of the exceedance probabilities at the unconditional mean of the covariates, I note that an increase in the number of exceedances in the US increases the probability of three-country exceedances in the EA. In addition, the conditional volatility of the US is helpful to predict exceedances in the Euro Area. The Wald statistic indicates that this variable is significant at the $1 \%$ level. This result holds for upper-tail events as well.

I use two more definitions of exceedances. Firstly, I define exceedances by the $2.5 \%$ quantile rather than the $5 \%$ quantile. Obviously, by proceeding this way there are fewer exceedances. Results (tables 20 and 21) from the multinomial logit model, are not sensitive to this alternative exceedance definition. Secondly, in order to allow for more general specification regarding the period of exceedances and their dynamics within a region, I reestimate (not reported) all the model regressions, but use exceedances computed over three days instead of over one day. In that way, I define coexceedance events as those in which more than one market experiences an extreme return within a three-day window. Once again, results, hardly differ from the original one in tables 6,7 and $8 .^{8}$

\section{Conclusion}

Using the concept of coexceedances of Bae et al. (2003), I have in this paper investigated if there is any evidence of contagion, first within the Euro Area region, and second, from the US to the EA. The fraction of EA coexceedances that cannot be explained by EA fundamentals-covrariates constitutes evidence of contagion. Similarly, the fraction of the coexceedances in Europe that is left unexplained by its own covariates, but that is explained by the exceedances from the US, implies contagion from the US to the EA. The results show that: a) the probability of extreme returns today is conditional upon the probability of extreme returns yesterday, extreme movements of stock prices followed by movements in the same direction; b) regional covariates, like bond yields and exchange rate do not seem to explain much about the probability of bottom-tail and top-tail events within the EA - consequently, there is evidence of contagion from these markets to the stock market;

\footnotetext{
${ }^{8}$ Results are available upon request.
} 
c) US exceedances fail to explain high probabilities of extreme negative returns in Europe - there is no statistically significant evidence of contagion effect from the US to the EA.

There is a long list of several extensions that would be accommodated in the framework and are likely to improve performance. First, it would be very interesting to implement this model in order to include other regions, like Asia and Latin America, and look for contagion in a global way. Second, one could consider alternative estimation approaches. It is well known, and mentioned by Bae et al. (2003), that multinomial models are unordered models, which means that they fail to account for the ordinal nature of the coexceedances. Other options could possibly include the use of extreme value theory, in the spirit of Longin and Solnik (2001) and Hartman et al. (2004), or the quantile regression analysis introduced by Koenker and Bassett (1978) and applied by Baur and Schulze (2005) and Cappiello et al. (2005) in financial contagion tests. Finally, another interesting issue would be to examine the out-of-sample exercise. What matters in a model is not its ability to produce an accurate in-sample fit, but rather its out-of-sample performance. In other words, a useful suggestion would be to test the forecasting properties of the model. 


\section{References}

[1] Ammer, J. and Jianping, M. (1996). Measuring International Economic Linkages with Stock Market Data. Journal of Finance, 51(5):1743-1763.

[2] Bae, K., Karolyi, A. and Stulz, R. (2003). A new Approach to Measuring Financial Contagion. Review of Financial Studies, 16(3):717-763.

[3] Baele, L., Ferrando, A., Hordahl, P., Krylova, E. and Monnet, C. (2004). Measuring Financial Integration in the Euro Area. European Central Bank Occasional Paper Series. No. 14.

[4] Baur, D. and Schulze, N. (2005). Coexceedances in Financial Markets - A Quantile Regression Analysis of Contagion. Emerging Markets Review, 6(1):21-43.

[5] Bekaert, G. and Harvey, C. (1995). Time-Varying World Market Integration. Journal of Finance, 50(2):403-444.

[6] Bekaert, G., Harvey, C. and Ng, A. (2005). Market Integration and Contagion. Journal of Business, 78(1):39-69.

[7] Berg, A and Pattillo, C. (1999). Predicting Currency Crises: The Indicators Approach and an Alternative. Journal of International Money and Finance, 18(4):561-586.

[8] Boyer, B., Gibson, M. and Loretan, M. (1999). Pitfalls in Tests for Changes in Correlations. International Finance Discussion Paper, 597.

[9] Caporale, G., Cipollini, A. and Spagnolo, N. (2005). Testing for Contagion: a Conditional Correlation Analysis. Journal of Empirical Finance, 12(3):476-489.

[10] Cappiello, L., Gerard, B. and Manganelli, S. (2005). Measuring Comovements by Regression Quantiles. ECB Working Paper, No. 501.

[11] Chan-Lau, J., Mathieson, D. and Yao, J. (2004). Extreme Contagion in Equity Markets. IMF Staff Paper, 51(2):386-408.

[12] Christiansen, C. and Ranaldo, A. (2009). Extreme Coexceedances in New EU Member States' Stock Markets. Journal of Banking and Finance, 33(6):1048-1057.

[13] Corsetti, G., Pericoli, M. and Sbracia, M. (2001). Correlation Analysis of Financial Contagion: What One Should Know before Running a Test. Temi di Discussion (Economics Working Papers), Banca d'Italia. 408:1-54.

[14] Cumperayot, P., Keijzer, T. and Kouwenberg, R. (2006). Linkages Between Extreme Stock Market and Currency Returns. Journal of International Money and Finance, 25(3):528550 .

[15] De Bondt, W. and Thaler, R. (1985). Does the Stock Market Overreact? Journal of Finance, 40(3):793-805.

[16] Dornbusch, R., Park, Y. P. and Claessens, S. (2000). Contagion: How it Spreads and How it can be Stopped. World Bank Research Observer, 15(2):177-197. 
[17] Dungey, M. and Martin, V. (2007). Unravelling Financial Market Linkages During Crises. Journal of Applied Econometrics, 22(1):89-119.

[18] Eichengreen, B., Rose, A. and Wyplosz, C. (1996). Contagious Currency Crises: First Tests. Scandinavian Journal of Economics, 98(4):463-484.

[19] Engle, R., Ito, T. and Lin, W (1990). Meteor Showers or Heat Waves? Heteroskedastic IntraDaily Volatility In the Foreign Exchange Market. Econometrica, 58(3):525-542.

[20] Fama, E. and French, K. (1996). Multifactor Explanations of Asset Pricing Anomalies. Journal of Finance, 51(1):55-84.

[21] Fazio, G. (2007). Extreme Interdependence and Extreme Contagion Between Emerging Markets. Journal of International Money and Finance, 26(8):1261-1291.

[22] Forbes, K. (2001). Are Trade Links Important Determinants of Country Vulnerability to Crises? National Bureau of Economic Research Working Papers, 8194:1-66.

[23] Forbes, K. and Rigobon, R. (2002). No Contagion, Only Interdependence: Measuring Stock Market Co-Movements. Journal of Finance, 57(5):2223-2261.

[24] Fratzscher, M. (2003). On Currency Crises and Contagion. International Journal of Finance and Economics, 8(2):109-129.

[25] Gilmore, C. and McManus, G. (2002). International Portfolio Diversification: US and Central European Equity Markets. Emerging Markets Review, 3(1):69-83.

[26] Greene, W. (2008). Econometric Analysis. Pearson International Edition, New Jersey.

[27] Gropp, R., Lo Duca, M. and Vesala, J. (2006). Cross-Border Bank Contagion in Europe. ECB Working Paper, No. 662.

[28] Guidolin, M. and Timmermann, A. (2005). Economic Implications of Bull and Bear Regimes in UK Stock and Bond Returns. Economic Journal, 115(500):111-143.

[29] Guidolin, M. and Timmermann, A. (2006). An Econometrics Model of Nonlinear Dynamics in the Joint Distribution of Stock and Bond Returns. Journal of Applied Econometrics, $21(1): 1-22$.

[30] Hamao, Y., Masulis, R. and Ng, V. (1990). Correlations in Price Changes and Volatility Across International Stock Markets. Review of Financial Studies, 3(2):281-307.

[31] Hardouvelis, G., Malliaropoulos, D. and Priestley, R. (2006). EMU and European Stock Market Integration. Journal of Business, 79(1):365-392.

[32] Hartmann, P., Straetmans, S. and De Vries, C. (2004). Asset Market Linkages in Crisis Periods. Review of Economics and Statistics, 86(1):313-326.

[33] Jeanne, O. and Masson, P. (2000). Currency Crises, Sunspots and Markov-Switching Regimes. Journal of International Economics, 50(2):327-350.

[34] Jegadeesh, N. (1990). Evidence of Predictable Behavior of Security Returns. Journal of Finance, 45(3):881-898. 
[35] Jegadeesh, N. and Titman, S. (1993). Returns to Buying Winners and Selling Losers: Implications for Stock Market Efficiency. Journal of Finance, 48(1):65-91.

[36] Kaminsky, G., Lizondo, S. and Reinhart, C. (1998). Leading Indicators of Currency Crises. IMF Staff Paper, 54(1):1-48.

[37] King, M. and Wadhwani, S. (1990). Transmission of Volatility between Stock Markets. Review of Financial Studies, 3(1):5-33.

[38] Koenker; R. and Bassett, G. (1978). Regression Quantiles. Econometrica, 46(1):33-50.

[39] Lehmann, L. (1990). Fads, Martingales and Market Efficiency. Quarterly Journal of Economics, 105(1):1-28.

[40] Loretan, M. and English, W. (2000). Evaluating Correlation Breakdowns During Periods of Market Volatility. International Finance Discussion Paper, 658.

[41] Lucey, B. and Sevic, A. (2010). Investigating the Determinants of Banking Coexceedances in Europe in the Summer of 2008. Journal of International Financial Markets, Institutions and Money, 20(3):275-283.

[42] Markwat, T., Kole, E. and Van Dijk, D. (2009). Contagion as a Domino Effect in Global Stock Markets. Journal of Banking and Finance, 33(11):1996-2012.

[43] McFadden, D. (1974). Conditional Logit Analysis of Quantile Choice Behavior. In: Zarembka, P. (Eds.), Frontiers in Econometrics. New York Academic Press, 105-142.

[44] Pesaran, H-M. and Pick, A. (2007). Econometric Issues in the Analysis of Contagion. Journal of Economic Dynamics and Control, 31(4):1245-1277.

[45] Ramchand, L. and Susmel, R. (1998). Volatility and Cross Correlation Across Major Stock Markets. Journal of Empirical Finance, 5(4):397-416.

[46] Rezayat, F. and Yavas, B. (2006). International Portfolio Diversification: A Study of Linkages Among the U.S., European and Japanese Equity Markets. Journal of Multinational Financial Management, 16(4):440-458.

[47] Rigobon, R. (2003). Identification Through Heteroscedasticity. Review of Economics and Statistics, MIT Press, 85(4):777-792.

[48] Roll, R. (1989). Price Volatility, International Market Links, and their Implications for Regulatory Policies. Journal of Financial Services Research, 3(2-3):247-254. 


\section{Appendix A}

Table 1. Data

\begin{tabular}{|c|c|c|}
\hline Variable & Source & Mnemonic/Code \\
\hline $\begin{array}{l}\text { Industrial Stock Return } \\
100 *\left[\ln \left(p_{t}\right)-\ln \left(p_{t-1}\right)\right]\end{array}$ & $\begin{array}{l}\text { Stock Market Industrial Index, } \\
\text { Datastream }\end{array}$ & $\begin{array}{l}\text { INDUS-OE(RI), -BG(RI), -CP(RI), } \\
\text {-FN(RI), -FR(RI),-BD(RI), -GR(RI), } \\
\text {-IR(RI), -IT(RI), -MA(RI), -NL(RI), } \\
\text {-PT(RI), -SJ(RI), -ES(RI), -EM(RI), } \\
\text {-US(RI) }\end{array}$ \\
\hline $\begin{array}{l}\text { Financial Stock Return } \\
100 *\left[\ln \left(p_{t}\right)-\ln \left(p_{t-1}\right)\right]\end{array}$ & $\begin{array}{l}\text { Stock Market Financial Index, } \\
\text { Datastream }\end{array}$ & FINANEM(RI), -US(RI) \\
\hline $\begin{array}{l}\text { Bond Yield } \\
100 *\left[\ln \left(p_{t}\right)-\ln \left(p_{t-1}\right)\right]\end{array}$ & $\begin{array}{l}10 \text { Yea Benchmark Bond Index, } \\
\text { Datastream }\end{array}$ & S08729(RY), S96475(RY \\
\hline $\begin{array}{l}\text { Change in Short-term } \\
\text { Interest Rate }\end{array}$ & $\begin{array}{l}\text { EURIBOR } 3 \text { Month, } \\
\text { Datastream }\end{array}$ & Y03728 \\
\hline \multicolumn{3}{|l|}{$p_{t}-p_{t-1}$} \\
\hline Exchange Rate & US to EURO & Y12764 \\
\hline $100 *\left[\ln \left(p_{t}\right)-\ln \left(p_{t-1}\right)\right]$ & Datastream & \\
\hline
\end{tabular}

Table 2. Descriptive Statistics of Daily Returns on the Industrial Stock Market Index, January 2, 2004, to July 11, 2012

\begin{tabular}{lcccccc}
\hline & AUS & BEL & CYP & FIN & FRA & GER \\
\hline Mean & 0.0410 & 0.0058 & -0.0343 & 0.0576 & 0.0307 & 0.0176 \\
Median & 0.0823 & 0.0776 & 0.0113 & 0.0971 & 0.0626 & 0.0676 \\
Maximum & 7.2556 & 9.4607 & 15.919 & 10.0217 & 10.5267 & 11.3452 \\
Minimum & -6.8762 & -8.4949 & -10.0463 & -8.8469 & -8.6128 & -10.9461 \\
Std. Dev. & 1.3262 & 1.5372 & 1.4386 & 1.7180 & 1.4779 & 1.5881 \\
Skewness & -0.6534 & -0.3934 & 0.5918 & -0.0465 & -0.0663 & -0.3396 \\
Kurtosis & 6.7534 & 7.0719 & 14.3736 & 6.2789 & 8.1378 & 9.4300 \\
Jarque-Bera & $1463.788^{* * *}$ & $1593.889^{* * *}$ & $12117.16^{* * *}$ & $997.0841^{* * *}$ & $2447.772^{* * *}$ & $3874.139^{* * *}$ \\
LB(5) & $40.926^{* * *}$ & $22.788^{* * *}$ & $9.7366^{*}$ & $14.120^{* *}$ & $13.585^{* *}$ & $12.354^{* *}$ \\
LB(5) squares & $1090.9^{* * *}$ & $983.97^{* * *}$ & $1146.4^{* * *}$ & $1059.3^{* * *}$ & $1109.6^{* * *}$ & $993.43^{* * *}$ \\
ADF & $-29.3514^{* * *}$ & $-42.8544^{* * *}$ & $-47.2255^{* * *}$ & $-45.4187^{* * *}$ & $-46.6178^{* * *}$ & $-45.2227^{* * *}$ \\
Observations & 2224 & 2224 & 2224 & 2224 & 2224 & 2224 \\
\hline \multicolumn{5}{c}{ Notes: * denotes significance at $10 \%, * *$ significance at $5 \%, * * *$ significance at $1 \%}$. &
\end{tabular}


Table 2 Cont. Descriptive Statistics of Daily Returns on the Industrial Stock Market Index, January 2, 2004, to July 11, 2012

\begin{tabular}{|c|c|c|c|c|c|c|}
\hline & GRE & IRE & ITA & MAL & NET & POR \\
\hline Mean & -0.0066 & 0.0518 & -0.0081 & 0.0568 & 0.0119 & 0.0121 \\
\hline Median & 0.0097 & 0.0003 & 0.0412 & 0.0210 & 0.0467 & 0.0457 \\
\hline Maximum & 10.5594 & 30.2040 & 6.9346 & 7.8288 & 10.3118 & 10.2696 \\
\hline Minimum & -17.3290 & -14.8419 & -8.1958 & -6.3757 & -9.4108 & -17.5869 \\
\hline Std. Dev. & 1.9028 & 2.3485 & 1.3777 & 1.0826 & 1.6227 & 1.3934 \\
\hline Skewness & -0.5401 & 0.9589 & -0.4008 & -0.0357 & -0.2422 & -0.9627 \\
\hline Kurtosis & 9.4672 & 18.7405 & 6.0327 & 12.3314 & 6.9977 & 19.0235 \\
\hline Jarque-Bera & $3983.926^{* * *}$ & $23300.47^{* * *}$ & $911.9051^{* * *}$ & $8069.469^{* * *}$ & $1502.746^{* * *}$ & $24135.96^{* * *}$ \\
\hline $\operatorname{LB}(5)$ & $30.100 * * *$ & 8.9718 & $10.409^{*}$ & $11.031^{*}$ & $21.327^{* * *}$ & $24.762^{* * *}$ \\
\hline $\mathrm{LB}(5)$ squares & $866.42^{* * *}$ & $1026.4^{* * *}$ & $1119.4^{* * *}$ & $941.49^{* * *}$ & $1043.0^{* * *}$ & $989.72^{* * *}$ \\
\hline $\mathrm{ADF}$ & $-42.5293^{* * *}$ & $-48.0227 * * *$ & $-45.5102 * * *$ & $-45.2467 * * *$ & $-43.6853^{* * *}$ & $-43.1789^{* * *}$ \\
\hline Observations & 2224 & 2224 & 2224 & 2224 & 2224 & 2224 \\
\hline
\end{tabular}

Table 2 Cont. Descriptive Statistics of Daily Returns on the Industrial Stock Market Index, January 2, 2004, to July 11, 2012

\begin{tabular}{lcccc}
\hline & SLO & SPA & EA & US \\
\hline Mean & -0.0688 & 0.0119 & 0.0183 & 0.0213 \\
Median & -0.0009 & 0.0803 & 0.0867 & 0.0605 \\
Maximum & 12.1809 & 8.0541 & 9.7730 & 9.0832 \\
Minimum & -9.0942 & -7.5817 & -8.1131 & -9.2310 \\
Std. Dev. & 1.6484 & 1.4295 & 1.3953 & 1.4717 \\
Skewness & -0.0022 & -0.3159 & -0.2474 & -0.2991 \\
Kurtosis & 8.0063 & 6.5257 & 7.8961 & 7.8778 \\
Jarque-Bera & $2322.546^{* * *}$ & $1188.939^{* * *}$ & $2244.131^{* * *}$ & $2238.038^{* * *}$ \\
LB(5) & $17.815^{* * *}$ & 2.3430 & $14.493^{* *}$ & $27.723^{* * *}$ \\
LB(5) squares & $1084.5^{* * *}$ & $1018.5^{* * *}$ & $1050.2^{* * *}$ & $1116.3^{* * *}$ \\
ADF & $-43.8801^{* * *}$ & $-46.3066^{* * *}$ & $-45.0905^{* * *}$ & $-52.5282^{* * *}$ \\
Observations & 2224 & 2224 & 2224 & 2224 \\
\hline Notes: ${ }^{*}$ denotes significance at $10 \%,{ }^{* *}$ significance at $5 \%,,^{* *}$ significance at $1 \%$.
\end{tabular}




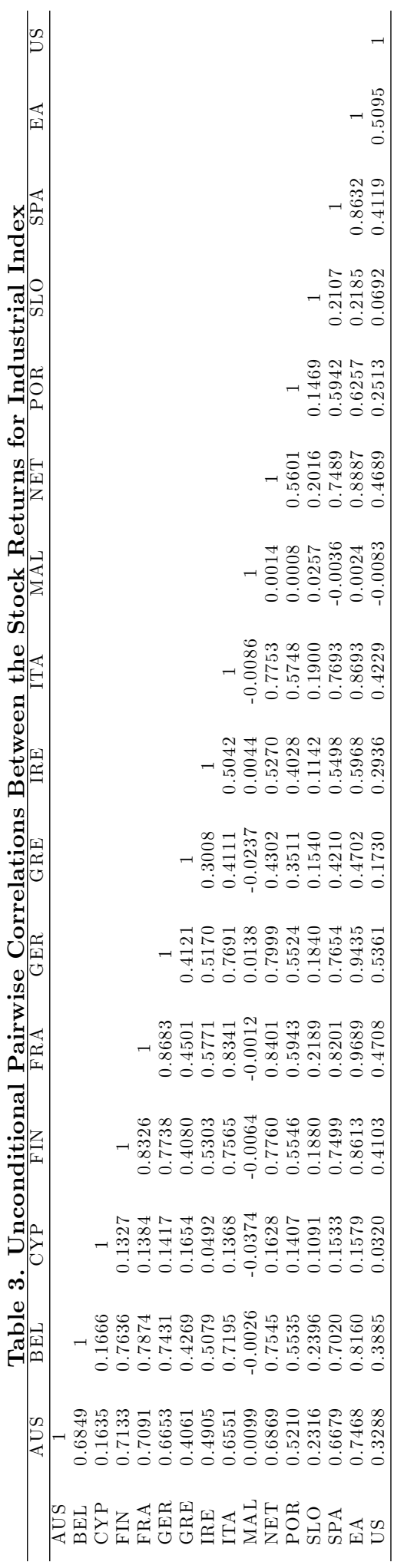




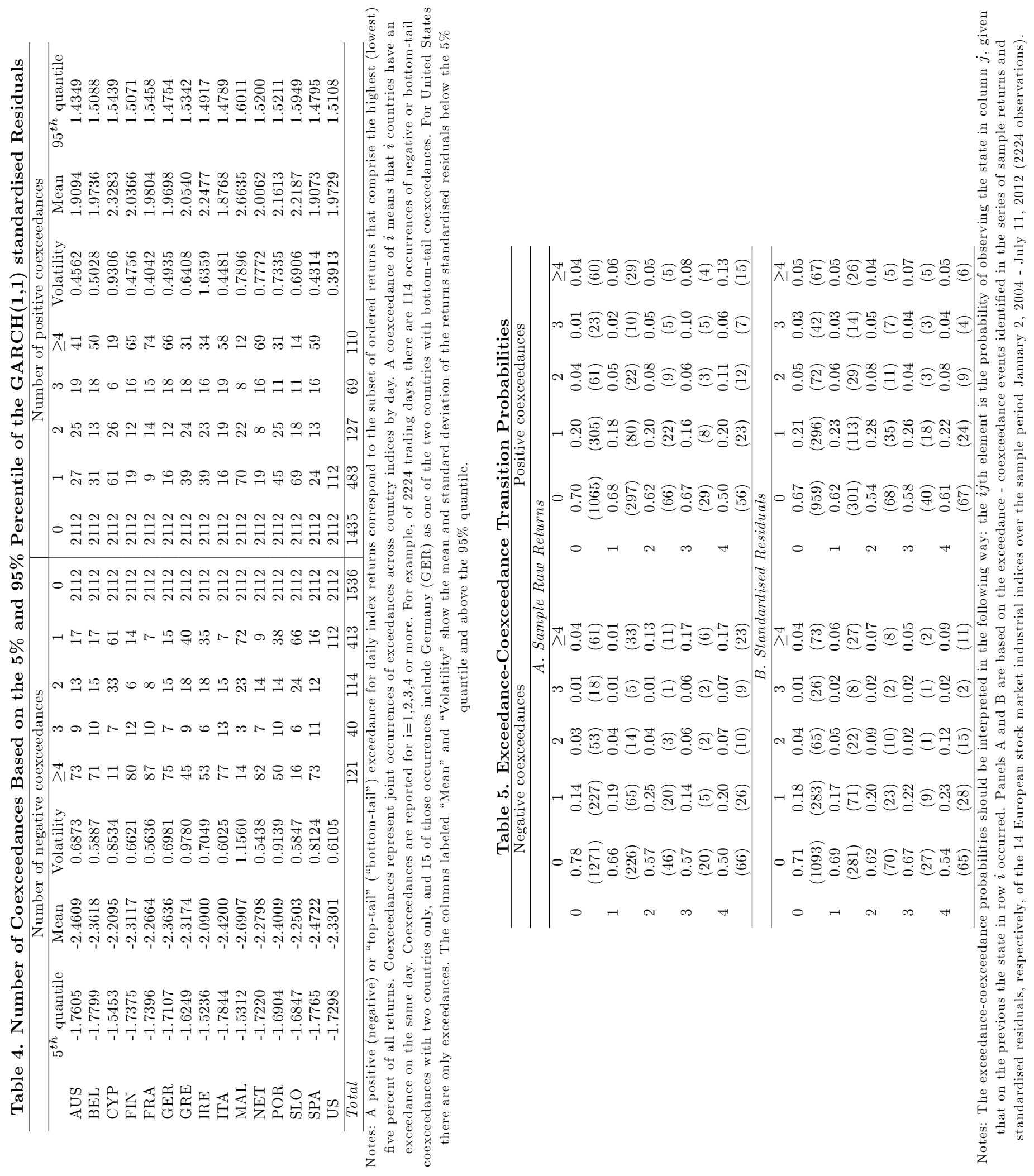




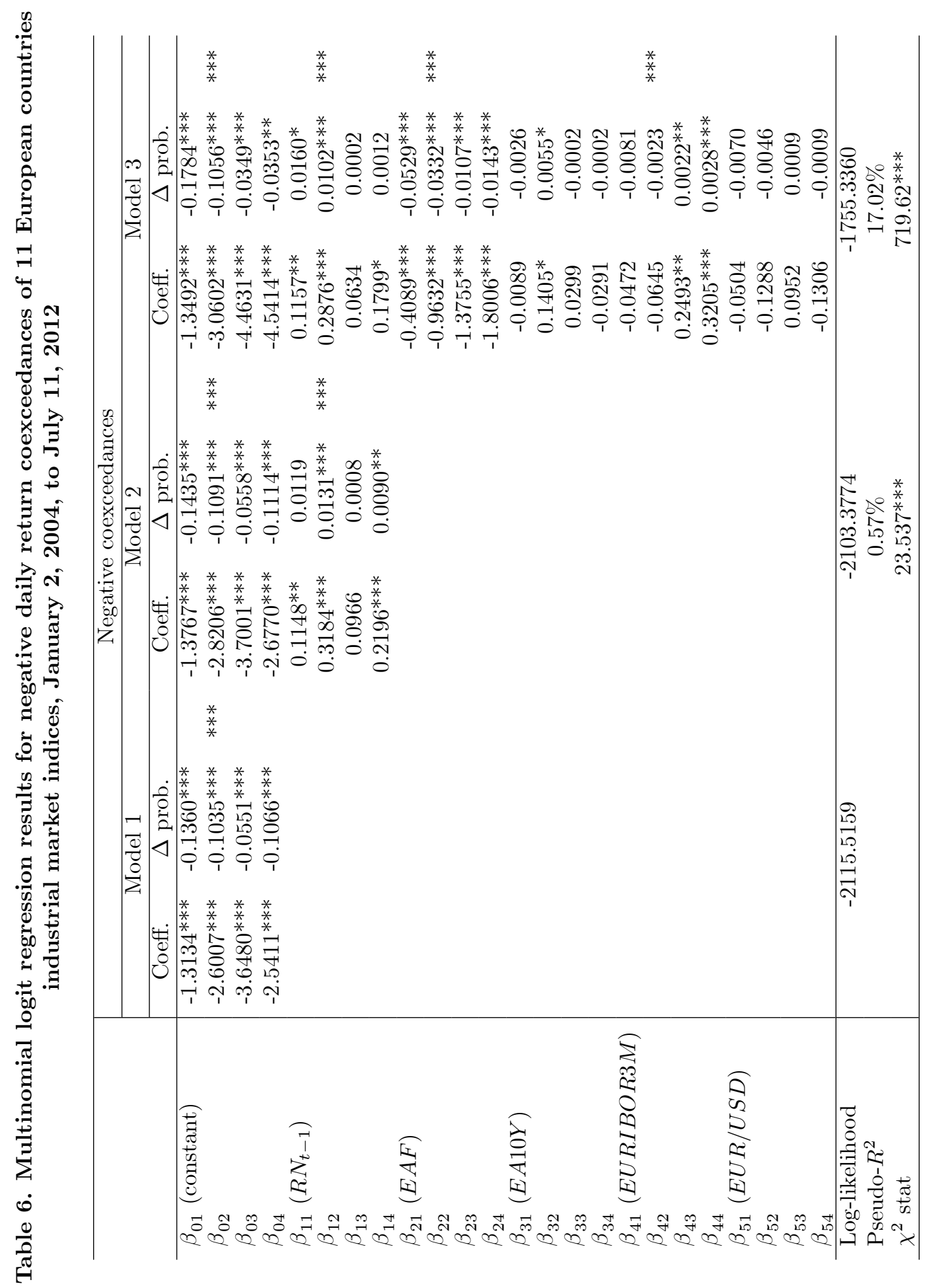




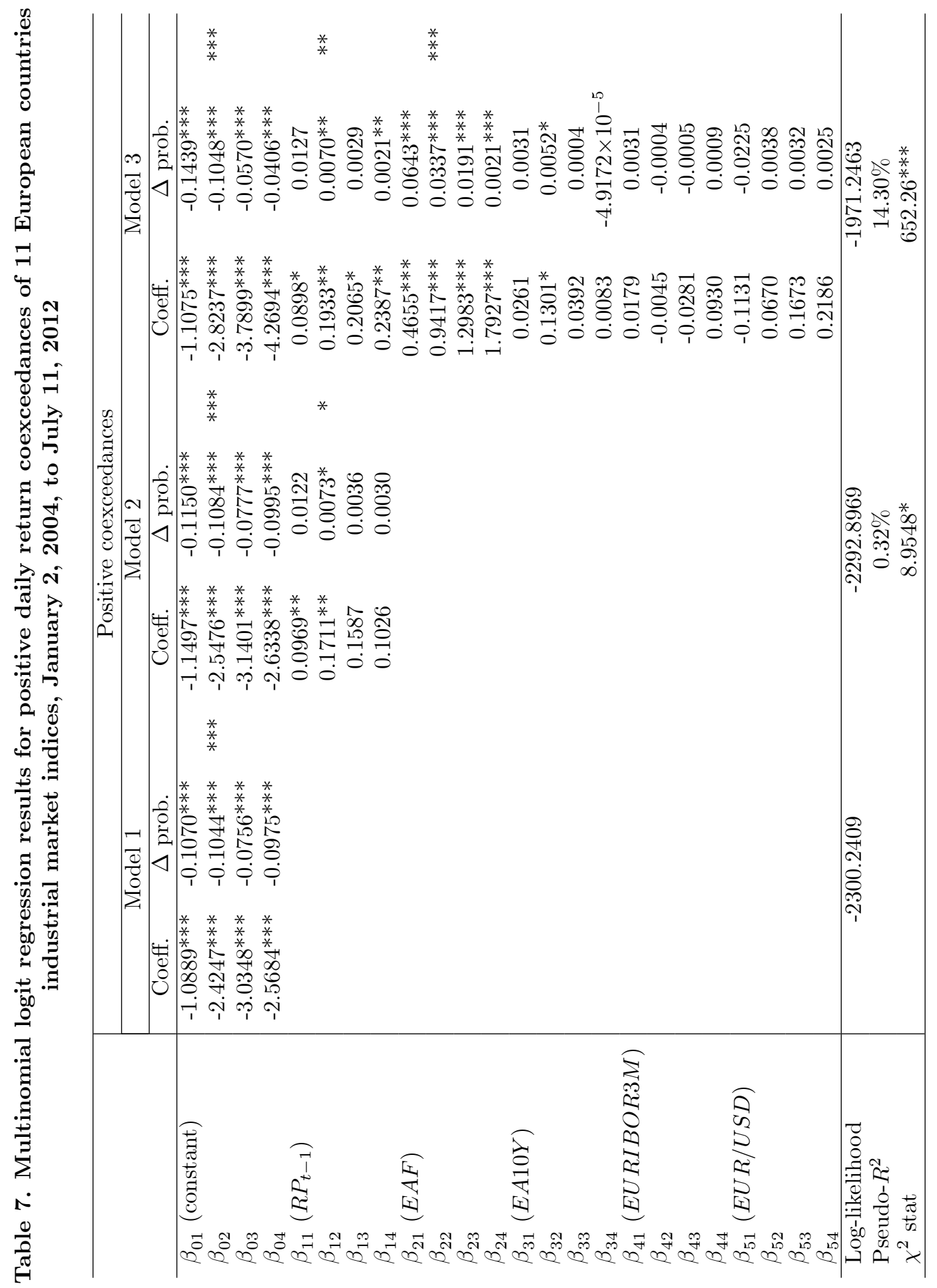


Table 8. Multinomial logit regression results for negative and positive daily return coexceedances of 11 European countries industrial market indices, January 2, 2004, to July 11, 2012

\begin{tabular}{|c|c|c|c|c|c|c|}
\hline & \multicolumn{3}{|c|}{ Negative coexceedances } & \multicolumn{3}{|c|}{ Positive coexceedances } \\
\hline & \multicolumn{6}{|c|}{ Model 4} \\
\hline & Coeff. & $\Delta$ prob. & & Coeff. & $\Delta$ prob. & \\
\hline$\beta_{01}$ (constant) & $-1.4036^{* * *}$ & $-0.2013^{* * *}$ & & $-0.4575^{* * *}$ & $-0.0529^{*}$ & \\
\hline$\beta_{02}$ & $-2.7984^{* * *}$ & $-0.0972^{* * *}$ & $* * *$ & $-1.9603^{* * *}$ & $-0.0736^{* * *}$ & $* * *$ \\
\hline$\beta_{03}$ & $-3.1251^{* * *}$ & $-0.0172^{* * *}$ & & $-2.4923^{* * *}$ & $-0.0304^{* * *}$ & \\
\hline$\beta_{04}$ & $-2.5511^{* * *}$ & $-0.0068^{* * *}$ & & $-1.9060^{* * *}$ & $-0.0070^{* * *}$ & \\
\hline$\beta_{11}\left(R N_{t-1} / R P_{t-1}\right)$ & $0.0981^{*}$ & 0.0140 & & 0.0804 & 0.0118 & \\
\hline$\beta_{12}$ & $0.2310^{* * *}$ & $0.0082^{* *}$ & $*$ & $0.1897^{* *}$ & $0.0067^{* *}$ & $* *$ \\
\hline$\beta_{13}$ & 0.0510 & 0.0001 & & 0.1703 & 0.0018 & \\
\hline$\beta_{14}$ & 0.1011 & 0.0002 & & $0.2534^{* *}$ & $0.0009^{* *}$ & \\
\hline$\beta_{21}(E A F)$ & $-0.3903^{* * *}$ & $-0.0525^{* * *}$ & & $0.4778^{* * *}$ & $0.0688^{* * *}$ & \\
\hline$\beta_{22}$ & $-0.9331^{* * *}$ & $-0.0327^{* * *}$ & $* * *$ & $1.0086^{* * *}$ & $0.0350^{* * *}$ & $* * *$ \\
\hline$\beta_{23}$ & $-1.6346^{* * *}$ & $-0.0095^{* * *}$ & & $1.4969^{* * *}$ & $0.0176^{* * *}$ & \\
\hline$\beta_{24}$ & $-2.3888^{* * *}$ & $-0.0073^{* * *}$ & & $2.4092^{* * *}$ & $0.0093^{* * *}$ & \\
\hline$\beta_{31}(E A 10 Y)$ & -0.0107 & -0.0031 & & 0.0283 & 0.0036 & \\
\hline$\beta_{32}$ & $0.1422^{*}$ & $0.0056^{*}$ & & $0.1419^{*}$ & $0.0055^{*}$ & \\
\hline$\beta_{33}$ & 0.0643 & 0.0003 & & 0.0362 & 0.0003 & \\
\hline$\beta_{34}$ & 0.0639 & 0.0001 & & -0.0646 & -0.0003 & \\
\hline$\beta_{41}(E U R I B O R 3 M)$ & -0.0303 & -0.0046 & & -0.0769 & -0.0115 & \\
\hline$\beta_{42}$ & -0.0726 & -0.0026 & & -0.1349 & -0.0045 & \\
\hline$\beta_{43}$ & 0.1337 & 0.009 & & $-0.2215^{*}$ & $-0.0026^{*}$ & \\
\hline$\beta_{44}$ & 0.1098 & 0.0003 & & $-0.2455^{* *}$ & $-0.0009^{*}$ & \\
\hline$\beta_{51}(E U R / U S D)$ & -0.0559 & -0.0078 & & -0.1062 & -0.0208 & \\
\hline$\beta_{52}$ & -0.1533 & -0.0055 & & -0.0793 & 0.0041 & \\
\hline$\beta_{53}$ & 0.0896 & 0.0006 & & 0.1952 & 0.0028 & \\
\hline$\beta_{54}$ & -0.2027 & -0.0006 & & 0.2857 & 0.0012 & \\
\hline$\beta_{61}\left(U S R N_{t-1} / U S R P_{t-1}\right)$ & 0.3608 & 0.0506 & & 0.3818 & 0.0610 & \\
\hline$\beta_{62}$ & $0.9022^{* *}$ & $0.0323^{* *}$ & $*$ & 0.2816 & 0.0067 & $* *$ \\
\hline$\beta_{63}$ & 0.3065 & 0.0012 & & $1.2283^{* * *}$ & $0.0149^{* * *}$ & \\
\hline$\beta_{64}$ & $0.8999^{*}$ & $0.0025^{*}$ & & $1.0852 * *$ & $0.0040 * *$ & \\
\hline$\beta_{71}\left(\right.$ USIvol $\left._{t-1}\right)$ & 0.0386 & 0.0114 & & $-0.5368^{* * *}$ & $-0.0828^{* * *}$ & \\
\hline$\beta_{72}$ & -0.2140 & -0.0081 & $* * *$ & $-0.7367^{* * *}$ & $-0.0234^{* * *}$ & $* * *$ \\
\hline$\beta_{73}$ & $-1.2890^{* * *}$ & $-0.0081^{* * *}$ & & $-1.2416^{* * *}$ & $-0.0142^{* * *}$ & \\
\hline$\beta_{74}$ & $-2.3016^{* * *}$ & $-0.0074^{* * *}$ & & $-2.6126^{* * *}$ & $-0.0102^{* * *}$ & \\
\hline Log-likelihood & & 718.9232 & & & 922.3871 & \\
\hline Pseudo- $R^{2}$ & & $18.74 \%$ & & & $16.42 \%$ & \\
\hline$\chi^{2}$ stat & & $91.7^{* * *}$ & & & $49.1^{* * *}$ & \\
\hline
\end{tabular}




\section{Appendix B}

Table 9. Multinomial logit regression results for negative and positive daily return coexceedances of 11 European countries industrial market indices, January 2, 2004, to July 11, 2012

\begin{tabular}{|c|c|c|c|c|c|c|}
\hline & \multicolumn{3}{|c|}{ Negative coexceedances } & \multicolumn{3}{|c|}{ Positive coexceedances } \\
\hline & \multicolumn{6}{|c|}{$\begin{array}{ll} & \text { Model } 4 \\
\end{array}$} \\
\hline & Coeff. & $\Delta$ prob. & & Coeff. & $\Delta$ prob. & \\
\hline$\beta_{01}($ constant $)$ & $-1.4278^{* * *}$ & $-0.2031^{* * *}$ & & $-0.4443^{* * *}$ & $-0.0493^{*}$ & \\
\hline$\beta_{02}$ & $-2.9224 * * *$ & $-0.1045^{* * *}$ & $* * *$ & $-1.9596^{* * *}$ & $-0.0729^{* * *}$ & $* * *$ \\
\hline$\beta_{03}$ & $-3.1436^{* * *}$ & $-0.0174^{* * *}$ & & $-2.6196 * * *$ & $-0.0353^{* * *}$ & \\
\hline$\beta_{04}$ & $-2.6767 * * *$ & $-0.0077 * * *$ & & $-1.8789 * * *$ & $-0.0071^{* * *}$ & \\
\hline$\beta_{11}\left(R N_{t-1} / R P_{t-1}\right)$ & $0.1127^{* *}$ & $0.0157^{*}$ & & $0.0932^{*}$ & 0.0136 & \\
\hline$\beta_{12}$ & $0.2910^{* * *}$ & $0.0107^{* * *}$ & $* * *$ & $0.2017^{* *}$ & $0.0070^{* *}$ & $* * *$ \\
\hline$\beta_{13}$ & 0.0971 & 0.0003 & & $0.2245^{* *}$ & $0.0028^{*}$ & \\
\hline$\beta_{14}$ & $0.2155^{*}$ & 0.0006 & & $0.3028^{* * *}$ & $0.0011^{* *}$ & \\
\hline$\beta_{21}(E A F)$ & $-0.3932^{* * *}$ & $-0.0528^{* * *}$ & & $0.4848^{* * *}$ & $0.0699^{* * *}$ & \\
\hline$\beta_{22}$ & $-0.9140 * * *$ & $-0.0327 * * *$ & $* * *$ & $0.9930^{* * *}$ & $0.0340^{* * *}$ & $* * *$ \\
\hline$\beta_{23}$ & $-1.6202^{* * *}$ & $-0.0096 * * *$ & & $1.4198^{* * *}$ & $0.0182^{* * *}$ & \\
\hline$\beta_{24}$ & $-2.3082^{* * *}$ & $-0.0075 * * *$ & & $2.3847^{* * *}$ & $0.0095^{* * *}$ & \\
\hline$\beta_{31}(E A 10 Y)$ & -0.0105 & -0.0030 & & 0.0304 & 0.0039 & \\
\hline$\beta_{32}$ & $0.1324^{*}$ & $0.0054^{*}$ & & $0.1397^{*}$ & $0.0053^{*}$ & \\
\hline$\beta_{33}$ & 0.0604 & 0.0003 & & 0.0494 & 0.0005 & \\
\hline$\beta_{34}$ & 0.0689 & 0.0002 & & -0.0571 & -0.0003 & \\
\hline$\beta_{41}(E U R I B O R 3 M)$ & -0.0259 & -0.0040 & & -0.0764 & -0.0112 & \\
\hline$\beta_{42}$ & -0.0528 & -0.0019 & & -0.1485 & -0.0050 & \\
\hline$\beta_{43}$ & 0.1313 & 0.0008 & & $-0.2120^{*}$ & -0.0027 & \\
\hline$\beta_{44}$ & 0.073 & 0.0003 & & $-0.2493^{* *}$ & $-0.0009^{*}$ & \\
\hline$\beta_{51}(E U R / U S D)$ & -0.0575 & -0.0081 & & -0.1268 & -0.0250 & \\
\hline$\beta_{52}$ & -0.1415 & -0.0052 & & 0.1201 & 0.0059 & \\
\hline$\beta_{53}$ & 0.1005 & 0.0007 & & 0.2213 & 0.0035 & \\
\hline$\beta_{54}$ & -0.2502 & -0.0008 & & 0.2920 & 0.0013 & \\
\hline$\beta_{61}(U S R N / U S R P)$ & 0.1851 & 0.0263 & & -0.1944 & -0.0437 & \\
\hline$\beta_{62}$ & 0.3659 & 0.0129 & & $0.6105^{*}$ & $0.0261^{*}$ & \\
\hline$\beta_{63}$ & 0.1851 & 0.0008 & & 0.6782 & 0.0101 & \\
\hline$\beta_{64}$ & $0.9485^{* *}$ & $0.0030^{* *}$ & & 0.3295 & 0.0014 & \\
\hline$\beta_{71}($ USIvol $)$ & 0.0588 & 0.0138 & & $-0.5345^{* * *}$ & $-0.0820 * * *$ & \\
\hline$\beta_{72}$ & -0.1006 & -0.0039 & $* * *$ & $-0.7643^{* * *}$ & $-0.0244 * * *$ & $* * *$ \\
\hline$\beta_{73}$ & $-1.2778^{* * *}$ & $-0.0082^{* * *}$ & & $-1.0776^{* * *}$ & $-0.0132 * * *$ & \\
\hline$\beta_{74}$ & $-2.2035^{* * *}$ & $-0.0076^{* * *}$ & & $-2.6029 * * *$ & $-0.0105^{* * *}$ & \\
\hline Log-likelihood & & 721.1083 & & & 925.9232 & \\
\hline Pseudo- $R^{2}$ & & $18.64 \%$ & & & $16.27 \%$ & \\
\hline$\chi^{2}$ stat & & $38.07 * * *$ & & & $42.9^{* * *}$ & \\
\hline
\end{tabular}


Table 10. Multinomial logit regression results for negative and positive daily return coexceedances of 11 European countries industrial market indices, January 2, 2004, to July 11, 2012

\begin{tabular}{|c|c|c|c|c|c|c|}
\hline & \multicolumn{3}{|c|}{ Negative coexceedances } & \multicolumn{3}{|c|}{ Positive coexceedances } \\
\hline & \multicolumn{6}{|c|}{ Model 4} \\
\hline & Coeff. & $\Delta$ prob. & & Coeff. & $\Delta$ prob. & \\
\hline$\beta_{01}($ constant $)$ & $-1.3803^{* * *}$ & $-0.1975^{* * *}$ & & $-0.4912 * * *$ & $-0.0573^{* *}$ & \\
\hline$\beta_{02}$ & $-2.7031 * * *$ & $-0.0935^{* * *}$ & $* * *$ & $-2.0594^{* * *}$ & $-0.0783^{* * *}$ & $* * *$ \\
\hline$\beta_{03}$ & $-3.0954^{* * *}$ & $-0.0169^{* * *}$ & & $-2.4480 * * *$ & $-0.0305^{* * *}$ & \\
\hline$\beta_{04}$ & $-2.7067 * * *$ & $-0.0086^{* * *}$ & & $-1.9718^{* * *}$ & $-0.0078 * * *$ & \\
\hline$\beta_{11}\left(R N_{t-1} / R P_{t-1}\right)$ & $0.1160^{* *}$ & $0.0162^{*}$ & & $0.0943^{*}$ & 0.0139 & \\
\hline$\beta_{12}$ & $0.2990^{* * *}$ & $0.0107^{* * *}$ & $* * *$ & $0.1989^{* *}$ & $0.0070^{* *}$ & $* *$ \\
\hline$\beta_{13}$ & 0.0686 & 0.0001 & & $0.2229^{* *}$ & $0.0026^{*}$ & \\
\hline$\beta_{14}$ & 0.1697 & 0.0005 & & $0.2839^{* *}$ & $0.0011^{* *}$ & \\
\hline$\beta_{21}(E A F)$ & $-0.3997 * * *$ & $-0.0535^{* * *}$ & & $0.4803^{* * *}$ & $0.0688^{* * *}$ & \\
\hline$\beta_{22}$ & $-0.9624^{* * *}$ & $-0.0337 * * *$ & $* * *$ & $0.9968 * * *$ & $0.0349 * * *$ & $* * *$ \\
\hline$\beta_{23}$ & $-1.6396^{* * *}$ & $-0.0095^{* * *}$ & & $1.5010^{* * *}$ & $0.0182^{* * *}$ & \\
\hline$\beta_{24}$ & $-2.3176^{* * *}$ & $-0.0082^{* * *}$ & & $2.3659^{* * *}$ & $0.0099^{* * *}$ & \\
\hline$\beta_{31}(E A 10 Y)$ & -0.0097 & -0.0028 & & 0.0262 & 0.0031 & \\
\hline$\beta_{32}$ & $0.1366^{*}$ & $0.0054^{*}$ & & $0.1440^{*}$ & $0.0056^{*}$ & \\
\hline$\beta_{33}$ & 0.0545 & 0.0003 & & 0.0476 & 0.0004 & \\
\hline$\beta_{34}$ & 0.0395 & 0.0001 & & -0.0539 & -0.0003 & \\
\hline$\beta_{41}(E U R I B O R 3 M)$ & -0.0329 & -0.0049 & & -0.0731 & -0.0109 & \\
\hline$\beta_{42}$ & -0.0850 & -0.0031 & & -0.1218 & -0.0041 & \\
\hline$\beta_{43}$ & 0.1204 & 0.0008 & & $-0.2308^{*}$ & $-0.0028^{*}$ & \\
\hline$\beta_{44}$ & 0.1157 & 0.0004 & & $-0.2271^{*}$ & $-0.0009^{*}$ & \\
\hline$\beta_{51}(E U R / U S D)$ & -0.0529 & -0.0076 & & -0.1052 & -0.0206 & \\
\hline$\beta_{52}$ & -0.1156 & -0.0041 & & 0.0804 & 0.0042 & \\
\hline$\beta_{53}$ & 0.0956 & 0.0007 & & 0.1890 & 0.0028 & \\
\hline$\beta_{54}$ & -0.1911 & -0.0006 & & 0.2972 & 0.0014 & \\
\hline$\beta_{61}\left(U S R N / U S R P_{t-3}\right)$ & 0.1135 & 0.0199 & & 0.2171 & 0.0429 & \\
\hline$\beta_{62}$ & -0.2337 & -0.0103 & & -0.1065 & -0.0061 & \\
\hline$\beta_{63}$ & 0.1359 & 0.0007 & & -0.4444 & -0.0066 & \\
\hline$\beta_{64}$ & 0.6939 & 0.0025 & & -1.2448 & -0.0058 & \\
\hline$\beta_{71}\left(\right.$ USIvol $\left._{t-3}\right)$ & 0.0200 & 0.0090 & & $-0.5126^{* * *}$ & $-0.0792 * * *$ & \\
\hline$\beta_{72}$ & -0.2743 & -0.0103 & $* * *$ & $-0.6385^{* * *}$ & $-0.0199^{* *}$ & $* * *$ \\
\hline$\beta_{73}$ & $-1.3192^{* * *}$ & $-0.0082^{* * *}$ & & $-1.2136^{* * *}$ & $-0.0144 * * *$ & \\
\hline$\beta_{74}$ & $-2.0874^{* * *}$ & $-0.0078^{* * *}$ & & $-2.4252^{* * *}$ & $-0.0102^{* * *}$ & \\
\hline Log-likelihood & & 722.1841 & & & 26.6335 & \\
\hline Pseudo- $R^{2}$ & & $18.59 \%$ & & & $6.24 \%$ & \\
\hline$\chi^{2}$ stat & & $1.07 * * *$ & & & $6.68^{* * *}$ & \\
\hline
\end{tabular}


Table 11. Multinomial logit regression results for negative and positive daily return coexceedances of 11 European countries industrial market indices, January 2, 2004, to July 11, 2012

\begin{tabular}{|c|c|c|c|c|c|c|}
\hline & \multicolumn{3}{|c|}{ Negative coexceedances } & \multicolumn{3}{|c|}{ Positive coexceedances } \\
\hline & \multicolumn{6}{|c|}{\begin{tabular}{|c|} 
Model 4 \\
\end{tabular}} \\
\hline & Coeff. & $\Delta$ prob. & & Coeff. & $\Delta$ prob. & \\
\hline$\beta_{01}($ constant $)$ & $-1.3822^{* * *}$ & $-0.1976^{* * *}$ & & $-0.5021 * * *$ & $-0.0591 * *$ & \\
\hline$\beta_{02}$ & $-2.7218^{* * *}$ & $-0.0942^{* * *}$ & $* * *$ & $-2.0988 * * *$ & $-0.0806 * * *$ & $* * *$ \\
\hline$\beta_{03}$ & $-3.0776^{* * *}$ & $-0.0164^{* * *}$ & & $-2.3832 * * *$ & $-0.0289 * * *$ & \\
\hline$\beta_{04}$ & $-2.6181^{* * *}$ & $-0.0083^{* * *}$ & & $-2.0194 * * *$ & $-0.0079 * * *$ & \\
\hline$\beta_{11}\left(R N_{t-1} / R P_{t-1}\right)$ & $0.1141^{* *}$ & $0.0160^{*}$ & & $0.0963^{*}$ & 0.0142 & \\
\hline$\beta_{12}$ & $0.2900 * * *$ & $0.0104^{* * *}$ & $* * *$ & $0.2002^{* *}$ & $0.0071^{* *}$ & $* * *$ \\
\hline$\beta_{13}$ & 0.0739 & 0.0002 & & $0.2309^{* *}$ & $0.0026^{*}$ & \\
\hline$\beta_{14}$ & 0.1497 & 0.0004 & & $0.2999^{* * *}$ & $0.0011^{* *}$ & \\
\hline$\beta_{21}(E A F)$ & $-0.4055^{* * *}$ & $-0.0543^{* * *}$ & & $0.4810^{* * *}$ & $0.0692^{* * *}$ & \\
\hline$\beta_{22}$ & $-0.9663^{* * *}$ & $-0.0338 * * *$ & $* * *$ & $0.9862^{* * *}$ & $0.0348^{* * *}$ & $* * *$ \\
\hline$\beta_{23}$ & $-1.6549^{* * *}$ & $-0.0093^{* * *}$ & & $1.5096^{* * *}$ & $0.0179 * * *$ & \\
\hline$\beta_{24}$ & $-2.3203^{* * *}$ & $-0.0082^{* * *}$ & & $2.3604^{* * *}$ & $0.0097 * * *$ & \\
\hline$\beta_{31}(E A 10 Y)$ & -0.0064 & -0.0023 & & 0.0265 & 0.0032 & \\
\hline$\beta_{32}$ & $0.1349^{*}$ & $0.0053^{*}$ & & $0.1414^{*}$ & $0.0056^{*}$ & \\
\hline$\beta_{33}$ & 0.0627 & 0.0003 & & 0.0435 & 0.0004 & \\
\hline$\beta_{34}$ & 0.0408 & 0.0001 & & -0.0551 & -0.0003 & \\
\hline$\beta_{41}(E U R I B O R 3 M)$ & -0.0367 & -0.0054 & & -0.0707 & -0.0105 & \\
\hline$\beta_{42}$ & -0.0940 & -0.0034 & & -0.1167 & -0.0039 & \\
\hline$\beta_{43}$ & 0.1274 & 0.0008 & & $-0.2440^{* *}$ & $-0.0029^{*}$ & \\
\hline$\beta_{44}$ & 0.1075 & 0.0004 & & $-0.2236^{*}$ & -0.0008 & \\
\hline$\beta_{51}(E U R / U S D)$ & -0.0563 & -0.0082 & & -0.1046 & -0.0207 & \\
\hline$\beta_{52}$ & -0.1107 & -0.0038 & & 0.0864 & 0.0045 & \\
\hline$\beta_{53}$ & 0.0985 & 0.0007 & & 0.1993 & 0.0029 & \\
\hline$\beta_{54}$ & -0.1758 & -0.0006 & & 0.3309 & 0.0015 & \\
\hline$\beta_{61}\left(U S R N / U S R P_{t-5}\right)$ & $0.6101 * *$ & $0.0936^{* *}$ & & -0.2450 & -0.0404 & \\
\hline$\beta_{62}$ & $0.8193^{* *}$ & $0.0271^{*}$ & $* *$ & -0.0934 & -0.0008 & \\
\hline$\beta_{63}$ & -0.6496 & -0.0050 & & -0.5401 & -0.0063 & \\
\hline$\beta_{64}$ & 0.4913 & 0.0012 & & -0.9613 & -0.0039 & \\
\hline$\beta_{71}\left(\right.$ USIvol $\left._{t-5}\right)$ & 0.0009 & 0.0060 & & $-0.4836^{* * *}$ & $-0.0743^{* * *}$ & \\
\hline$\beta_{72}$ & -0.2992 & -0.0111 & $* * *$ & $-0.6006^{* * *}$ & $-0.0188^{* *}$ & $* * *$ \\
\hline$\beta_{73}$ & $-1.3220^{* * *}$ & $-0.0080^{* * *}$ & & $-1.2779^{* * *}$ & $-0.0150 * * *$ & \\
\hline$\beta_{74}$ & $-2.1377^{* * *}$ & $-0.0080^{* * *}$ & & $-2.4132^{* * *}$ & $-0.0100^{* * *}$ & \\
\hline Log-likelihood & & 715.5163 & & & 925.8793 & \\
\hline Pseudo- $R^{2}$ & & $18.90 \%$ & & & $16.27 \%$ & \\
\hline$\chi^{2}$ stat & & $90.3^{* * *}$ & & & $31.29 * * *$ & \\
\hline
\end{tabular}


Table 12. Multinomial logit regression results for negative and positive daily return coexceedances of 11 European countries industrial market indices, January 2, 2004, to July 11, 2012

\begin{tabular}{|c|c|c|c|c|c|c|}
\hline & \multicolumn{3}{|c|}{ Negative coexceedances } & \multicolumn{3}{|c|}{ Positive coexceedances } \\
\hline & \multicolumn{6}{|c|}{ Model 3} \\
\hline & Coeff. & $\Delta$ prob. & & Coeff. & $\Delta$ prob. & \\
\hline$\beta_{01}($ constant $)$ & $-1.3584^{* * *}$ & $-0.1855^{* * *}$ & & $-1.0800^{* * *}$ & $-0.0480 * * *$ & \\
\hline$\beta_{02}$ & $-3.0674^{* * *}$ & $-0.1042^{* * *}$ & $* * *$ & $-2.8074^{* * *}$ & $-0.1150^{* * *}$ & $* * *$ \\
\hline$\beta_{03}$ & $-4.4621^{* * *}$ & $-0.0208^{* * *}$ & & $-3.7542^{* * *}$ & $-0.0695^{* * *}$ & \\
\hline$\beta_{04}$ & $-4.5557^{* * *}$ & $-0.0314^{* * *}$ & & $-4.2767^{* * *}$ & $-0.0432^{* * *}$ & \\
\hline$\beta_{11}\left(R N_{t-1} / R P_{t-1}\right)$ & $0.1151^{* *}$ & $0.0156^{*}$ & & 0.0736 & 0.0032 & \\
\hline$\beta_{12}$ & $0.3205^{* * *}$ & $0.0112^{* * *}$ & $* * *$ & $0.2236^{* * *}$ & $0.0092^{* *}$ & $* * *$ \\
\hline$\beta_{13}$ & 0.1429 & 0.0005 & & $0.2253^{* *}$ & $0.0041^{*}$ & \\
\hline$\beta_{14}$ & $0.2563^{* *}$ & $0.0016^{* *}$ & & $0.2973^{* * *}$ & $0.0030 * * *$ & \\
\hline$\beta_{21}(E A F)$ & $-0.4022^{* * *}$ & $-0.0532^{* * *}$ & & $0.4683^{* * *}$ & $0.0219 * * *$ & \\
\hline$\beta_{22}$ & $-0.9838 * * *$ & $-0.0335^{* * *}$ & $* * *$ & $0.9549 * * *$ & $0.0385^{* * *}$ & $* * *$ \\
\hline$\beta_{23}$ & $-1.5123^{* * *}$ & $-0.0071^{* * *}$ & & $1.3154^{* * *}$ & $0.0241 * * *$ & \\
\hline$\beta_{24}$ & $-1.8954^{* * *}$ & $-0.0134 * * *$ & & $1.8862^{* * *}$ & $0.0192^{* * *}$ & \\
\hline$\beta_{31}(E A 10 Y)$ & -0.0090 & -0.0025 & & 0.0165 & 0.0004 & \\
\hline$\beta_{32}$ & $0.1349^{*}$ & $0.0052^{*}$ & & $0.1561^{* *}$ & $0.0067^{* *}$ & \\
\hline$\beta_{33}$ & 0.0394 & 0.0001 & & 0.0470 & 0.0007 & \\
\hline$\beta_{34}$ & -0.0267 & -0.0002 & & 0.0323 & 0.0002 & \\
\hline$\beta_{41}(E U R I B O R 3 M)$ & -0.0154 & -0.0020 & & 0.0519 & 0.0029 & \\
\hline$\beta_{42}$ & -0.1167 & -0.0044 & * & -0.0018 & -0.0003 & \\
\hline$\beta_{43}$ & 0.0802 & 0.0004 & & 0.0059 & $9.3656 \times 10^{-6}$ & \\
\hline$\beta_{44}$ & $0.2273^{* *}$ & $0.0017^{* *}$ & & $0.1948^{*}$ & $0.0020^{*}$ & \\
\hline$\beta_{51}(E U R / U S D)$ & -0.05425 & -0.0075 & & -0.1191 & -0.0076 & \\
\hline$\beta_{51}$ & -0.1251 & -0.0043 & & 0.0751 & 0.0034 & \\
\hline$\beta_{53}$ & 0.1113 & 0.0006 & & 0.1631 & 0.0032 & \\
\hline$\beta_{54}$ & -0.1195 & -0.0007 & & 0.2020 & 0.0021 & \\
\hline$\beta_{61}(E A 10 Y$ dummyt-1 $)$ & 0.0146 & 0.0129 & & 0.3317 & $0.0242^{*}$ & \\
\hline$\beta_{62}$ & -0.7717 & -0.0289 & $*$ & $-0.8689^{*}$ & $-0.0378^{*}$ & $* * *$ \\
\hline$\beta_{63}$ & $-1.8604^{*}$ & $-0.0094^{*}$ & & -0.4832 & -0.0087 & \\
\hline$\beta_{64}$ & $-1.3760^{* *}$ & $-0.0102^{* *}$ & & $-2.0711^{* * *}$ & $-0.0220 * * *$ & \\
\hline$\beta_{71}(E U R I B O R 3 M$ dummyt-1 $)$ & 0.2752 & 0.0624 & & $-0.7007^{* *}$ & $-0.0383^{* *}$ & \\
\hline$\beta_{72}$ & -0.6554 & -0.0251 & & -0.2946 & -0.0092 & $* *$ \\
\hline$\beta_{73}$ & -9.0735 & -0.0480 & & -0.6655 & -0.0115 & \\
\hline$\beta_{74}$ & $-1.2856^{*}$ & $-0.0096^{*}$ & & $-2.1223^{* *}$ & $-0.0221^{* *}$ & \\
\hline$\beta_{81}(E U R / U S D$ dummyt-1) & -0.0477 & -0.0100 & & $-3423.64 * * *$ & $-201.87 * * *$ & \\
\hline$\beta_{82}$ & 0.5120 & 0.0204 & & $-380.063^{* * *}$ & $-6.6219^{* * *}$ & $* * *$ \\
\hline$\beta_{83}$ & -0.8724 & -0.0045 & & $-112.237^{* * *}$ & $2.5258^{* * *}$ & \\
\hline$\beta_{84}$ & -0.6748 & -0.0051 & & $-18.3762^{* * *}$ & $2.3894^{* * *}$ & \\
\hline Log-likelihood & & 742.2647 & & & 1955.6297 & \\
\hline Pseudo- $R^{2}$ & & $17.64 \%$ & & & $14.98 \%$ & \\
\hline$\chi^{2}$ stat & & $45.76^{* * *}$ & & & $83.49^{* * *}$ & \\
\hline
\end{tabular}


Table 13. Multinomial logit regression results for negative and positive daily return coexceedances of 11 European countries industrial market indices, January 2, 2004, to July 11, 2012

\begin{tabular}{|c|c|c|c|c|c|c|}
\hline & \multicolumn{3}{|c|}{ Negative coexceedances } & \multicolumn{3}{|c|}{ Positive coexceedances } \\
\hline & \multicolumn{6}{|c|}{$\begin{array}{ll}\text { Model } 3 \\
\end{array}$} \\
\hline & Coeff. & $\Delta$ prob. & & Coeff. & $\Delta$ prob. & \\
\hline$\beta_{01}($ constant $)$ & $-1.3606^{* * *}$ & $-0.1897 * * *$ & & $-1.0483^{* * *}$ & $-0.1269 * * *$ & \\
\hline$\beta_{02}$ & $-3.0548 * * *$ & $-0.1080^{* * *}$ & $* * *$ & $-2.7765^{* * *}$ & $-0.1049^{* * *}$ & $* * *$ \\
\hline$\beta_{03}$ & $-4.3952 * * *$ & $-0.0013^{* * *}$ & & $-3.7422^{* * *}$ & $-0.0523^{* * *}$ & \\
\hline$\beta_{04}$ & $-4.5231 * * *$ & $-0.0324 * * *$ & & $-4.2628 * * *$ & $-0.0376^{* * *}$ & \\
\hline$\beta_{11}\left(R N_{t-1} / R P_{t-1}\right)$ & $0.1158^{* *}$ & $0.0162 *$ & & $0.0876^{*}$ & 0.0116 & \\
\hline$\beta_{21}$ & $0.2895^{* * *}$ & $0.0104^{* * *}$ & $* * *$ & $0.1909^{* *}$ & $0.0071^{* *}$ & $* *$ \\
\hline$\beta_{13}$ & 0.0461 & $2.9966 \times 10^{-6}$ & & $0.1955^{*}$ & 0.0025 & \\
\hline$\beta_{14}$ & 0.1531 & 0.0009 & & $0.2264^{* *}$ & $0.0019^{*}$ & \\
\hline$\beta_{21}(E A F)$ & $-0.4079^{* * *}$ & $-0.0556^{* * *}$ & & $0.4681^{* * *}$ & $0.0607^{* * *}$ & \\
\hline$\beta_{22}$ & $-0.9643^{* * *}$ & $-0.0341 * * *$ & $* * *$ & $0.9430^{* * *}$ & $0.0343^{* * *}$ & $* * *$ \\
\hline$\beta_{23}$ & $-1.4870^{* * *}$ & $-0.0004^{* * *}$ & & $1.3480^{* * *}$ & $0.0185^{* * *}$ & \\
\hline$\beta_{24}$ & $-1.8754^{* * *}$ & $-0.0137 * * *$ & & $1.8470^{* * *}$ & $0.0164^{* * *}$ & \\
\hline$\beta_{31}(E A 10 Y)$ & -0.0061 & -0.0021 & & 0.0304 & 0.0034 & \\
\hline$\beta_{32}$ & $0.1420^{*}$ & $0.0057^{*}$ & & $0.1374^{*}$ & $0.0055^{*}$ & \\
\hline$\beta_{33}$ & 0.0339 & $9.9538 \times 10^{-6}$ & & 0.0681 & 0.0008 & \\
\hline$\beta_{34}$ & -0.0261 & -0.0002 & & 0.0383 & 0.0002 & \\
\hline$\beta_{41}(E U R I B O R 3 M)$ & -0.0480 & -0.0076 & & 0.0277 & 0.0046 & \\
\hline$\beta_{42}$ & -0.0786 & -0.0027 & $* *$ & -0.0072 & -0.0005 & \\
\hline$\beta_{43}$ & 0.1297 & $4.7516 \times 10^{-5}$ & & -0.0499 & -0.0008 & \\
\hline$\beta_{44}$ & $0.2585^{* * *}$ & $0.0021^{* * *}$ & & 0.0848 & 0.0007 & \\
\hline$\beta_{51}(E U R / U S D)$ & -0.0545 & -0.0077 & & -0.1171 & -0.0214 & \\
\hline$\beta_{52}$ & -0.1198 & -0.0042 & & 0.0689 & 0.0038 & \\
\hline$\beta_{53}$ & 0.0967 & $3.8473 \times 10^{-5}$ & & 0.1951 & 0.0033 & \\
\hline$\beta_{54}$ & -0.1421 & -0.0009 & & 0.2622 & 0.0027 & \\
\hline$\beta_{61}\left(E A 10 Y\right.$ dummyt-5 $\left._{t}\right)$ & 0.2282 & 0.0374 & & $-0.5158^{*}$ & -0.0686 & \\
\hline$\beta_{62}$ & 0.2033 & 0.0064 & & -0.5654 & -0.0168 & $* *$ \\
\hline$\beta_{63}$ & -1.2492 & -0.0004 & & $-2.4900^{* *}$ & $-0.0365^{* *}$ & \\
\hline$\beta_{64}$ & -0.9388 & -0.0078 & & $-1.7187 * * *$ & $-0.0150 * *$ & \\
\hline$\beta_{71}(E U R I B O R 3 M$ dummyt-5) & -0.1232 & -0.0124 & & $-0.7950^{* * *}$ & $-0.1258^{* * *}$ & \\
\hline$\beta_{72}$ & -0.3261 & -0.0108 & & -0.4005 & -0.0090 & $*$ \\
\hline$\beta_{73}$ & $-38.0166^{* * *}$ & $-0.0127 * * *$ & & -0.5062 & -0.0048 & \\
\hline$\beta_{74}$ & $-1.4341^{* *}$ & $-0.0108^{* *}$ & & -0.5990 & -0.0039 & \\
\hline$\beta_{81}\left(E U R / U S D\right.$ dummyt-5 $\left._{t}\right)$ & 0.1045 & 0.0191 & & $-327.308^{* * *}$ & $-53.618 * * *$ & \\
\hline$\beta_{82}$ & -0.0172 & -0.0012 & & $-85.1460 * * *$ & $-0.5091 * * *$ & $* * *$ \\
\hline$\beta_{83}$ & $-27.9417^{* * *}$ & $-0.0094^{* * *}$ & & $-35.1611^{* * *}$ & $0.6147^{* * *}$ & \\
\hline$\beta_{84}$ & 0.1105 & 0.0007 & & $-21.6649^{* * *}$ & $0.5146^{* * *}$ & \\
\hline Log-likelihood & & 1742.3953 & & & 52.5896 & \\
\hline Pseudo- $R^{2}$ & & $17.63 \%$ & & & $5.11 \%$ & \\
\hline$\chi^{2}$ stat & & $39.91^{* * *}$ & & & $3.75^{* * *}$ & \\
\hline
\end{tabular}


Table 14. Multinomial logit regression results for negative and positive daily return coexceedances of 11 European countries industrial market indices, January 2, 2004, to May 31, 2007

\begin{tabular}{|c|c|c|c|c|c|c|}
\hline & \multicolumn{3}{|c|}{ Negative coexceedances } & \multicolumn{3}{|c|}{ Positive coexceedances } \\
\hline & \multicolumn{6}{|c|}{ Model 3} \\
\hline & Coeff. & $\Delta$ prob. & & Coeff. & $\Delta$ prob. & \\
\hline$\beta_{01}$ (constant) & $-1.1809^{* * *}$ & $-0.1652^{* * *}$ & & $-0.7530^{* * *}$ & $-0.0785^{* * *}$ & \\
\hline$\beta_{02}$ & $-2.8356^{* * *}$ & $-0.0897 * * *$ & $* * *$ & $-2.4523^{* * *}$ & $-0.1352^{* * *}$ & $* * *$ \\
\hline$\beta_{03}$ & $-5.0786^{* * *}$ & $-0.0174^{* * *}$ & & $-4.1278^{* * *}$ & $-0.0532^{* * *}$ & \\
\hline$\beta_{04}$ & $-7.0400^{* * *}$ & $-0.0032^{* * *}$ & & $-5.1139^{* * *}$ & $-0.0324^{* * *}$ & \\
\hline$\beta_{11}\left(R N_{t-1} / R P_{t-1}\right)$ & -0.0048 & -0.0017 & & 0.0664 & 0.0060 & \\
\hline$\beta_{12}$ & 0.1456 & 0.0051 & & $0.2347^{*}$ & $0.0129 *$ & $* * *$ \\
\hline$\beta_{13}$ & -0.1814 & -0.0006 & & $0.3813^{* *}$ & $0.0049^{*}$ & \\
\hline$\beta_{14}$ & 0.2674 & 0.0001 & & $0.6609^{* * *}$ & $0.0043^{* * *}$ & \\
\hline$\beta_{21}(E A F)$ & $-0.7087 * * *$ & $-0.0971^{* * *}$ & & $0.7747^{* * *}$ & $0.1122^{* * *}$ & \\
\hline$\beta_{22}$ & $-1.9539 * * *$ & $-0.0626^{* * *}$ & $* * *$ & $1.5056^{* * *}$ & $0.0760^{* * *}$ & $* * *$ \\
\hline$\beta_{23}$ & $-3.2043^{* * *}$ & $-0.0109 * * *$ & & $2.7379^{* * *}$ & $0.0342^{* * *}$ & \\
\hline$\beta_{24}$ & $-4.8289^{* * *}$ & $-0.0022^{* * *}$ & & $3.6575^{* * *}$ & $0.0228^{* * *}$ & \\
\hline$\beta_{31}(E A 10 Y)$ & 0.0487 & 0.0065 & & 0.0297 & 0.0048 & \\
\hline$\beta_{32}$ & 0.2245 & 0.0075 & $*$ & 0.1275 & 0.0078 & \\
\hline$\beta_{33}$ & -0.3971 & -0.0015 & & -0.2946 & -0.0045 & \\
\hline$\beta_{43}$ & $-0.8921^{* *}$ & $-0.0004^{* *}$ & & 0.0384 & 0.0001 & \\
\hline$\beta_{41}(E U R I B O R 3 M)$ & $-0.3410^{* *}$ & $-0.0520^{* *}$ & & -0.1939 & -0.0382 & \\
\hline$\beta_{42}$ & $-0.4490^{*}$ & $-0.0132^{*}$ & $* *$ & -0.0155 & 0.0036 & \\
\hline$\beta_{43}$ & $0.5131^{*}$ & $0.0022^{* *}$ & & -0.3447 & -0.0040 & \\
\hline$\beta_{44}$ & -0.1020 & $-9.0049 \times 10^{-6}$ & & -0.4192 & -0.0024 & \\
\hline$\beta_{51}(E U R / U S D)$ & -0.1960 & -0.0269 & & $-0.2651^{*}$ & $-0.0575^{*}$ & \\
\hline$\beta_{52}$ & $-0.5073^{*}$ & -0.0161 & $*$ & 0.1003 & 0.0121 & \\
\hline$\beta_{53}$ & $-1.1828^{* *}$ & $-0.0041^{* *}$ & & -0.0917 & -0.0002 & \\
\hline$\beta_{54}$ & $-0.9634^{*}$ & -0.0004 & & -0.1027 & -0.0001 & \\
\hline Log-likelihood & & -638.8298 & & & 372.7635 & \\
\hline Pseudo- $R^{2}$ & & $17.48 \%$ & & & $11.25 \%$ & \\
\hline$\chi^{2}$ stat & & $270.12^{* * *}$ & & & $16.21^{* * *}$ & \\
\hline
\end{tabular}


Table 15. Multinomial logit regression results for negative and positive daily return coexceedances of 11 European countries industrial market indices, January 2, 2004, to May 31, 2007

\begin{tabular}{|c|c|c|c|c|c|c|}
\hline & \multicolumn{3}{|c|}{ Negative coexceedances } & \multicolumn{3}{|c|}{ Positive coexceedances } \\
\hline & \multicolumn{6}{|c|}{ Model 4} \\
\hline & Coeff. & $\Delta$ prob. & & Coeff. & $\Delta$ prob. & \\
\hline$\beta_{01}($ constant $)$ & $-1.8336^{* * *}$ & $-0.2549^{* * *}$ & & -0.7003 & -0.0911 & \\
\hline$\beta_{02}$ & $-5.0273^{* * *}$ & $-0.1545^{* * *}$ & $* * *$ & $-2.1789^{* * *}$ & $-0.1235^{* *}$ & $*$ \\
\hline$\beta_{03}$ & $-8.8446^{* * *}$ & $-0.0280^{* * *}$ & & -2.2349 & -0.0238 & \\
\hline$\beta_{04}$ & $-7.8307 * * *$ & $-0.0032^{* * *}$ & & -1.4398 & -0.0055 & \\
\hline$\beta_{11}\left(R N_{t-1} / R P_{t-1}\right)$ & -0.0343 & -0.0053 & & 0.0682 & 0.0078 & \\
\hline$\beta_{12}$ & 0.0008 & 0.0003 & & $0.2128^{*}$ & 0.0118 & $* *$ \\
\hline$\beta_{13}$ & -0.3150 & -0.0010 & & 0.2849 & 0.0031 & \\
\hline$\beta_{14}$ & 0.2028 & $9.5818 \times 10^{-5}$ & & $0.5849^{* * *}$ & $0.0029^{* * *}$ & \\
\hline$\beta_{21}(E A F)$ & $-0.7157^{* * *}$ & $-0.0996^{* * *}$ & & $0.7736^{* * *}$ & $0.2251^{* * *}$ & \\
\hline$\beta_{22}$ & $-1.9450^{* * *}$ & $-0.0597 * * *$ & $* * *$ & $1.4935^{* * *}$ & $0.0762^{* * *}$ & $* * *$ \\
\hline$\beta_{23}$ & $-3.1410^{* * *}$ & $-0.0098^{* * *}$ & & $2.7658^{* * *}$ & $0.0307^{* * *}$ & \\
\hline$\beta_{24}$ & $-4.8914^{* * *}$ & $-0.0021^{* * *}$ & & $3.8617^{* * *}$ & $0.0186^{* * *}$ & \\
\hline$\beta_{31}(E A 10 Y)$ & 0.0487 & 0.0068 & & 0.0290 & 0.0048 & \\
\hline$\beta_{32}$ & 0.2148 & 0.0069 & $*$ & 0.1214 & 0.0075 & \\
\hline$\beta_{33}$ & -0.4779 & -0.0016 & & -0.3272 & -0.0044 & \\
\hline$\beta_{34}$ & $-0.9202^{* *}$ & $-0.0004^{* *}$ & & 0.0353 & 0.0001 & \\
\hline$\beta_{41}(E U R I B O R 3 M)$ & $-0.3064^{* *}$ & $-0.0471^{*}$ & & -0.1951 & -0.0387 & \\
\hline$\beta_{42}$ & $-0.4081^{*}$ & -0.0115 & * & -0.0202 & 0.0033 & \\
\hline$\beta_{43}$ & $0.4930^{*}$ & $0.0019^{* *}$ & & -0.3568 & -0.0037 & \\
\hline$\beta_{44}$ & -0.0566 & $8.3242 \times 10^{-6}$ & & $-0.5283^{*}$ & -0.0024 & \\
\hline$\beta_{51}(E U R / U S D)$ & -0.2128 & -0.0296 & & -0.2560 & $-0.0563^{*}$ & \\
\hline$\beta_{52}$ & $-0.5709^{*}$ & $-0.0175^{*}$ & $*$ & 0.1225 & 0.0135 & \\
\hline$\beta_{53}$ & $-1.0787^{* *}$ & $-0.0034^{*}$ & & -0.0808 & -0.0001 & \\
\hline$\beta_{54}$ & $-1.0383^{*}$ & $-0.0004^{*}$ & & -0.1738 & -0.0005 & \\
\hline$\beta_{61}\left(U S R N / U S R P_{t-1}\right)$ & 0.4359 & 0.0604 & & 0.2181 & 0.0181 & \\
\hline$\beta_{62}$ & $1.3500^{*}$ & $0.0420^{*}$ & & 0.8458 & 0.0477 & $* *$ \\
\hline$\beta_{63}$ & 0.9838 & 0.0028 & & $1.9387^{* * *}$ & $0.0231^{* * *}$ & \\
\hline$\beta_{64}$ & 0.5993 & 0.0002 & & $1.4691^{* *}$ & $0.0070^{* *}$ & \\
\hline$\beta_{71}\left(\right.$ USIvol $\left._{t-1}\right)$ & 0.6631 & 0.0892 & & -0.0583 & 0.0087 & \\
\hline$\beta_{72}$ & $2.1997^{* *}$ & $0.0686^{* *}$ & $* *$ & -0.2931 & -0.0143 & \\
\hline$\beta_{73}$ & $3.7750^{* *}$ & $0.0120^{* *}$ & & -2.0730 & -0.0258 & \\
\hline$\beta_{74}$ & 0.7444 & 0.0002 & & $-4.0220^{* *}$ & $-0.0211^{* *}$ & \\
\hline Log-likelihood & & -632.2362 & & & 361.8604 & \\
\hline Pseudo- $R^{2}$ & & $18.34 \%$ & & & $12.36 \%$ & \\
\hline$\chi^{2}$ stat & & $282.64^{* * *}$ & & & $36.9^{* * *}$ & \\
\hline
\end{tabular}


Table 16. Multinomial logit regression results for negative and positive daily return coexceedances of 11 European countries industrial market indices, June 1, 2007, to July 11, 2012

\begin{tabular}{|c|c|c|c|c|c|c|}
\hline & \multicolumn{3}{|c|}{ Negative coexceedances } & \multicolumn{3}{|c|}{ Positive coexceedances } \\
\hline & \multicolumn{6}{|c|}{ Model 3} \\
\hline & Coeff. & $\Delta$ prob. & & Coeff. & $\Delta$ prob. & \\
\hline$\beta_{01}($ constant $)$ & $-1.3951^{* * *}$ & $-0.1869^{* * *}$ & & $-1.3717^{* * *}$ & $-0.1838^{* * *}$ & \\
\hline$\beta_{02}$ & $-3.2479 * * *$ & $-0.1066^{* * *}$ & $* * *$ & $-3.3944^{* * *}$ & $-0.0769^{* * *}$ & $* * *$ \\
\hline$\beta_{03}$ & $-4.5730^{* * *}$ & $-0.0352^{* * *}$ & & $-4.0450^{* * *}$ & $-0.0463^{* * *}$ & \\
\hline$\beta_{04}$ & $-4.4544^{* * *}$ & $-0.0395 * * *$ & & $-4.7571^{* * *}$ & $-0.0235^{* * *}$ & \\
\hline$\beta_{11}\left(R N_{t-1} / R P_{t-1}\right)$ & $0.1683^{* * *}$ & $0.0242^{* *}$ & & 0.0916 & 0.0135 & \\
\hline$\beta_{12}$ & $0.3692^{* * *}$ & $0.0123^{* * *}$ & $* * *$ & 0.1350 & 0.0029 & \\
\hline$\beta_{13}$ & 0.1393 & 0.0007 & & -0.0948 & 0.0009 & \\
\hline$\beta_{14}$ & 0.1715 & 0.0011 & & -0.0068 & -0.0001 & \\
\hline$\beta_{21}(E A F)$ & $-0.3553^{* * *}$ & $-0.0463^{* * *}$ & & $0.3793^{* * *}$ & $0.0505^{* * *}$ & \\
\hline$\beta_{22}$ & $-0.8522^{* * *}$ & $-0.0279^{* * *}$ & $* * *$ & $0.9120^{* * *}$ & $0.0205^{* * *}$ & $* * *$ \\
\hline$\beta_{23}$ & $-1.2118^{* * *}$ & $-0.0093^{* * *}$ & & $1.1209^{* * *}$ & $0.0128^{* * *}$ & \\
\hline$\beta_{24}$ & $-1.5780^{* * *}$ & $-0.0144^{* * *}$ & & $1.7212^{* * *}$ & $0.0087^{* * *}$ & \\
\hline$\beta_{31}(E A 10 Y)$ & -0.0375 & -0.0065 & & 0.0420 & 0.0049 & \\
\hline$\beta_{32}$ & 0.0728 & -0.0030 & & $0.2109^{* *}$ & $0.0050^{* *}$ & \\
\hline$\beta_{33}$ & -0.0483 & -0.0003 & & $0.1804^{*}$ & 0.0021 & \\
\hline$\beta_{34}$ & -0.0835 & -0.0007 & & 0.1098 & 0.0005 & \\
\hline$\beta_{41}(E U R I B O R 3 M)$ & -0.0147 & -0.0029 & & 0.0016 & 0.0009 & \\
\hline$\beta_{42}$ & -0.0570 & -0.0021 & $* * *$ & -0.1265 & -0.0031 & \\
\hline$\beta_{43}$ & 0.1901 & $0.0016^{*}$ & & -0.0731 & -0.0008 & \\
\hline$\beta_{44}$ & $0.3034^{* * *}$ & $0.0030^{* * *}$ & & 0.0887 & 0.0005 & \\
\hline$\beta_{51}(E U R / U S D)$ & 0.0042 & 0.0008 & & 0.0031 & -0.0022 & \\
\hline$\beta_{52}$ & -0.0463 & -0.0018 & & 0.1871 & 0.0044 & $*$ \\
\hline$\beta_{53}$ & 0.3373 & 0.0029 & & $0.4419^{*}$ & $0.0054^{*}$ & \\
\hline$\beta_{54}$ & -0.1985 & -0.0019 & & $0.6267^{* *}$ & $0.0033^{* * *}$ & \\
\hline Log-likelihood & & 67.1715 & & & 035.1653 & \\
\hline Pseudo- $R^{2}$ & & $9.76 \%$ & & & $19.72 \%$ & \\
\hline$\chi^{2}$ stat & & $5.61^{* * *}$ & & & $8.66^{* * *}$ & \\
\hline
\end{tabular}


Table 17. Multinomial logit regression results for negative and positive daily return coexceedances of 11 European countries industrial market indices, June 1, 2007, to July 11, 2012

\begin{tabular}{|c|c|c|c|c|c|c|}
\hline & \multicolumn{3}{|c|}{ Negative coexceedances } & \multicolumn{3}{|c|}{ Positive coexceedances } \\
\hline & \multicolumn{6}{|c|}{ Model 4} \\
\hline & Coeff. & $\Delta$ prob. & & Coeff. & $\Delta$ prob. & \\
\hline$\beta_{01}($ constant $)$ & $-1.5118^{* * *}$ & $-0.2206^{* * *}$ & & $-0.9451^{* * *}$ & $-0.1248^{* * *}$ & \\
\hline$\beta_{02}$ & $-3.1455^{* * *}$ & $-0.1062^{* * *}$ & $* * *$ & $-2.8943^{* * *}$ & $-0.0663^{* * *}$ & $* * *$ \\
\hline$\beta_{03}$ & $-3.0419 * * *$ & $-0.0135^{* * *}$ & & $-3.2173^{* * *}$ & $-0.0340 * * *$ & \\
\hline$\beta_{04}$ & $-2.6339 * * *$ & $-0.0072^{* * *}$ & & $-2.8265^{* * *}$ & $-0.0057^{* * *}$ & \\
\hline$\beta_{11}\left(R N_{t-1} / R P_{t-1}\right)$ & $0.1514^{* *}$ & $0.0224^{* *}$ & & 0.0772 & 0.0111 & \\
\hline$\beta_{12}$ & $0.3127^{* * *}$ & $0.0106^{* * *}$ & $* *$ & 0.1467 & 0.0032 & \\
\hline$\beta_{13}$ & 0.1223 & 0.0004 & & 0.0927 & 0.0008 & \\
\hline$\beta_{14}$ & 0.0915 & 0.0001 & & 0.0148 & $-1.1207 \times 10^{-5}$ & \\
\hline$\beta_{21}(E A F)$ & $-0.3413^{* * *}$ & $-0.0470 * * *$ & & $0.3830^{* * *}$ & $0.0515^{* * *}$ & \\
\hline$\beta_{22}$ & $-0.8080^{* * *}$ & $-0.0273^{* * *}$ & $* * *$ & $0.9281^{* * *}$ & $0.0207^{* * *}$ & $* * *$ \\
\hline$\beta_{23}$ & $-1.5104^{* * *}$ & $-0.0073^{* * *}$ & & $1.1971^{* * *}$ & $0.0126^{* * *}$ & \\
\hline$\beta_{24}$ & $-2.1118^{* * *}$ & $-0.0066^{* * *}$ & & $2.1616^{* * *}$ & $0.0046^{* * *}$ & \\
\hline$\beta_{31}(E A 10 Y)$ & -0.0387 & -0.0071 & & 0.0406 & 0.0048 & \\
\hline$\beta_{32}$ & 0.0699 & 0.0029 & & $0.2171^{* *}$ & $0.0051^{* *}$ & \\
\hline$\beta_{33}$ & 0.0180 & 0.0001 & & 0.1698 & 0.0018 & \\
\hline$\beta_{34}$ & 0.0398 & 0.0001 & & 0.0135 & $-4.2756 \times 10^{-6}$ & \\
\hline$\beta_{41}(E U R I B O R 3 M)$ & 0.0043 & 0.0009 & & -0.0558 & -0.0071 & \\
\hline$\beta_{42}$ & -0.0480 & -0.0018 & & $-0.1925^{*}$ & $-0.0044^{*}$ & \\
\hline$\beta_{43}$ & 0.0474 & 0.0002 & & -0.1802 & -0.0018 & \\
\hline$\beta_{44}$ & 0.1172 & 0.0003 & & -0.1593 & -0.0003 & \\
\hline$\beta_{51}(E U R / U S D)$ & 0.0004 & 0.0002 & & 0.0166 & 0.0004 & \\
\hline$\beta_{52}$ & -0.0553 & -0.0021 & & 0.1779 & 0.0041 & * \\
\hline$\beta_{53}$ & 0.4433 & 0.0023 & & 0.4335 & 0.0048 & \\
\hline$\beta_{54}$ & -0.2157 & -0.0007 & & $0.6938^{* * *}$ & $0.0015^{* * *}$ & \\
\hline$\beta_{61}\left(U S R N / U S R P_{t-1}\right)$ & 0.3303 & 0.0475 & & $0.5655^{*}$ & $0.0881^{*}$ & \\
\hline$\beta_{62}$ & $0.8320^{* *}$ & $0.0288^{*}$ & & -0.2214 & -0.0084 & \\
\hline$\beta_{63}$ & 0.0864 & -0.0001 & & 0.4896 & 0.0044 & \\
\hline$\beta_{64}$ & 0.6798 & 0.0019 & & 0.3739 & 0.0005 & \\
\hline$\beta_{71}\left(\right.$ USIvol $\left._{t-1}\right)$ & 0.0758 & 0.0161 & & $-0.3201^{* *}$ & $-0.0459^{* *}$ & \\
\hline$\beta_{72}$ & -0.0656 & -0.0025 & $* * *$ & -0.3529 & -0.0069 & $* * *$ \\
\hline$\beta_{73}$ & $-1.3747^{* * *}$ & $-0.0072^{* * *}$ & & $-0.6466^{* *}$ & $-0.0065^{*}$ & \\
\hline$\beta_{74}$ & $-1.9685^{* * *}$ & $-0.0066^{* * *}$ & & $-1.8995^{* * *}$ & $-0.0041^{* * *}$ & \\
\hline Log-likelihood & & 041.3059 & & & -1015.9221 & \\
\hline Pseudo- $R^{2}$ & & $21.70 \%$ & & & $21.25 \%$ & \\
\hline$\chi^{2}$ stat & & $77.34^{* * *}$ & & & $547.14^{* * *}$ & \\
\hline
\end{tabular}


Table 18. Multinomial logit regression results for negative and positive daily return coexceedances (computed on sample returns) of 11 European countries industrial market indices, January 2, 2004, to July 11, 2012

\begin{tabular}{|c|c|c|c|c|c|c|}
\hline & \multicolumn{3}{|c|}{ Negative coexceedances } & \multicolumn{3}{|c|}{ Positive coexceedances } \\
\hline & \multicolumn{6}{|c|}{ Model 3} \\
\hline & Coeff. & $\Delta$ prob. & & Coeff. & $\Delta$ prob. & \\
\hline$\beta_{01}($ constant $)$ & $-1.6440 * * *$ & $-0.2139^{* * *}$ & & $-1.2375^{* * *}$ & $-0.1783^{* * *}$ & \\
\hline$\beta_{02}$ & $-3.5806^{* * *}$ & $-0.0852^{* * *}$ & $* * *$ & $-2.3092^{* * *}$ & $-0.0944^{* * *}$ & $* * *$ \\
\hline$\beta_{03}$ & $-5.4086^{* * *}$ & $-0.0256^{* * *}$ & & $-4.9042^{* * *}$ & $-0.0326^{* * *}$ & \\
\hline$\beta_{04}$ & $-6.5019^{* * *}$ & $-0.0097^{* * *}$ & & $-5.7943^{* * *}$ & $-0.0148^{* * *}$ & \\
\hline$\beta_{11}\left(R N_{t-1} / R P_{t-1}\right)$ & $0.2400^{* * *}$ & $0.0324^{* * *}$ & & 0.0771 & 0.0094 & \\
\hline$\beta_{12}$ & $0.3201^{* * *}$ & $0.0071^{* * *}$ & $* * *$ & $0.3816^{* * *}$ & $0.0114^{* * *}$ & $* * *$ \\
\hline$\beta_{13}$ & $0.6441^{* * *}$ & $0.0030^{* * *}$ & & $0.5213^{* * *}$ & $0.0035^{* * *}$ & \\
\hline$\beta_{14}$ & $0.5015^{* * *}$ & $0.0007^{* * *}$ & & $0.4083^{* * *}$ & $0.0010^{* * *}$ & \\
\hline$\beta_{21}(E A F)$ & $-0.3124^{* * *}$ & $-0.0392^{* * *}$ & & $0.3870^{* * *}$ & $0.0544^{* * *}$ & \\
\hline$\beta_{22}$ & $-0.8272^{* * *}$ & $-0.0199^{* * *}$ & $* * *$ & $1.1301^{* * *}$ & $0.0324^{* * *}$ & $* * *$ \\
\hline$\beta_{23}$ & $-1.4293^{* * *}$ & $-0.0068^{* * *}$ & & $1.6631^{* * *}$ & $0.0111^{* * *}$ & \\
\hline$\beta_{24}$ & $-2.6429 * * *$ & $-0.0040^{* * *}$ & & $2.4257^{* * *}$ & $0.0063^{* * *}$ & \\
\hline$\beta_{31}(E A 10 Y)$ & 0.0226 & 0.0045 & & 0.0617 & 0.0098 & \\
\hline$\beta_{32}$ & $-0.1900^{* *}$ & $-0.0050^{* *}$ & $* *$ & 0.0863 & 0.0022 & \\
\hline$\beta_{33}$ & $-0.3343^{* * *}$ & $-0.0017 * * *$ & & 0.0392 & 0.0001 & \\
\hline$\beta_{34}$ & -0.1164 & -0.0001 & & $0.2134^{* *}$ & $0.0005^{* *}$ & \\
\hline$\beta_{41}(E U R I B O R 3 M)$ & $-0.1262^{* * *}$ & $-0.0172^{* *}$ & & $-0.1212^{* * *}$ & $-0.0192^{* *}$ & \\
\hline$\beta_{42}$ & $-0.2111^{* * *}$ & $-0.0049^{* * *}$ & $* * *$ & -0.1123 & -0.0025 & $* * *$ \\
\hline$\beta_{43}$ & -0.0134 & $7.3671 \times 10^{-5}$ & & $-0.3776^{* * *}$ & $-0.0025^{* * *}$ & \\
\hline$\beta_{44}$ & 0.0717 & 0.0001 & & $-0.4561^{* * *}$ & $-0.0011^{* * *}$ & \\
\hline$\beta_{51}(E U R / U S D)$ & -0.0915 & -0.0099 & & -0.0352 & -0.0095 & \\
\hline$\beta_{52}$ & $-0.7095^{* * *}$ & $-0.0182^{* * *}$ & $* * *$ & $0.3935^{* *}$ & $0.0126^{* *}$ & $*$ \\
\hline$\beta_{53}$ & 0.0767 & 0.0005 & & 0.3525 & 0.0025 & \\
\hline$\beta_{54}$ & -0.1460 & -0.0001 & & 0.0584 & 0.0001 & \\
\hline Log-likelihood & & 1457.0941 & & & 712.5521 & \\
\hline Pseudo- $R^{2}$ & & $24.89 \%$ & & & $20.24 \%$ & \\
\hline$\chi^{2}$ stat & & $65.27^{* * *}$ & & & $1.69^{* * *}$ & \\
\hline
\end{tabular}


Table 19. Multinomial logit regression results for negative and positive daily return coexceedances (computed on sample returns) of 11 European countries industrial market indices, January 2, 2004, to July 11, 2012

\begin{tabular}{|c|c|c|c|c|c|c|}
\hline & \multicolumn{3}{|c|}{ Negative coexceedances } & \multicolumn{3}{|c|}{ Positive coexceedances } \\
\hline & \multicolumn{6}{|c|}{ Model 4} \\
\hline & Coeff. & $\Delta$ prob. & & Coeff. & $\Delta$ prob. & \\
\hline$\beta_{01}$ (constant) & $-2.2605^{* * *}$ & $-0.3000^{* * *}$ & & $-1.3465^{* * *}$ & $-0.1902^{* * *}$ & \\
\hline$\beta_{02}$ & $-4.8669 * * *$ & $-0.1121^{* * *}$ & $* * *$ & $-3.9546^{* * *}$ & $-0.1176^{* * *}$ & $* * *$ \\
\hline$\beta_{03}$ & $-6.3538 * * *$ & $-0.0281^{* * *}$ & & $-5.3245^{* * *}$ & $-0.0367^{* * *}$ & \\
\hline$\beta_{04}$ & $-8.2019^{* * *}$ & $-0.0116^{* * *}$ & & $-6.9144^{* * *}$ & $-0.0178^{* * *}$ & \\
\hline$\beta_{11}\left(R N_{t-1} / R P_{t-1}\right)$ & $0.1963^{* * *}$ & $0.0272^{* * *}$ & & 0.0716 & 0.0092 & \\
\hline$\beta_{12}$ & $0.1968^{*}$ & 0.0040 & $* * *$ & $0.3016^{* * *}$ & $0.0092^{* * *}$ & $* * *$ \\
\hline$\beta_{13}$ & $0.4339^{* * *}$ & $0.0019^{* * *}$ & & $0.4409^{* * *}$ & $0.0031^{* * *}$ & \\
\hline$\beta_{14}$ & $0.3786^{* * *}$ & $0.0005^{* * *}$ & & $0.2639^{* *}$ & $0.0006^{*}$ & \\
\hline$\beta_{21}(E A F)$ & $-0.3489^{* * *}$ & $-0.0449 * * *$ & & $0.3936^{* * *}$ & $0.0558^{* * *}$ & \\
\hline$\beta_{22}$ & $-0.8802^{* * *}$ & $-0.0204^{* * *}$ & $* * *$ & $1.0880^{* * *}$ & $0.0321^{* * *}$ & $* * *$ \\
\hline$\beta_{23}$ & $-1.4246^{* * *}$ & $-0.0064^{* * *}$ & & $1.6286^{* * *}$ & $0.0113^{* * *}$ & \\
\hline$\beta_{24}$ & $-2.6140 * * *$ & $-0.0038^{* * *}$ & & $2.3147^{* * *}$ & $0.0006^{* * *}$ & \\
\hline$\beta_{31}(E A 10 Y)$ & 0.0259 & 0.0049 & & 0.0597 & 0.0095 & \\
\hline$\beta_{32}$ & $-0.1792^{* *}$ & $-0.0046^{* *}$ & $* *$ & 0.0852 & 0.0023 & $*$ \\
\hline$\beta_{33}$ & $-0.3393^{* * *}$ & $-0.0016^{* * *}$ & & 0.0276 & $7.9866 \times 10^{-5}$ & \\
\hline$\beta_{34}$ & -0.1273 & -0.0001 & & $0.2463^{* *}$ & $0.0006^{* *}$ & \\
\hline$\beta_{41}(E U R I B O R 3 M)$ & -0.0332 & -0.0049 & & $-0.1078^{* *}$ & $-0.0180 * *$ & \\
\hline$\beta_{42}$ & -0.0179 & -0.0003 & $*$ & -0.0037 & 0.0007 & $* *$ \\
\hline$\beta_{43}$ & 0.1174 & 0.0005 & & $-0.2785^{* *}$ & $-0.0019^{* *}$ & \\
\hline$\beta_{44}$ & $0.2465 * * *$ & $0.0003^{* * *}$ & & $-0.2276^{* *}$ & $-0.0005^{*}$ & \\
\hline$\beta_{51}(E U R / U S D)$ & -0.1135 & -0.0124 & & -0.0356 & -0.0095 & \\
\hline$\beta_{52}$ & $-0.6602^{* * *}$ & $-0.0162^{* * *}$ & $* * *$ & $0.3632^{* *}$ & $0.0121^{* *}$ & \\
\hline$\beta_{53}$ & -0.0428 & $-2.3820 \times 10^{-5}$ & & 0.3404 & 0.0025 & \\
\hline$\beta_{54}$ & -0.2165 & -0.0002 & & 0.0974 & 0.0002 & \\
\hline$\beta_{61}\left(U S R N_{t-1} / U S R P_{t-1}\right)$ & 0.0682 & 0.0071 & & -0.0035 & -0.0020 & \\
\hline$\beta_{62}$ & 0.3721 & 0.0089 & & 0.0854 & 0.0027 & \\
\hline$\beta_{63}$ & $1.2706^{* *}$ & $0.0060^{* *}$ & & 0.3404 & 0.0025 & \\
\hline$\beta_{64}$ & -0.1294 & -0.0002 & & 0.2460 & 0.0006 & \\
\hline$\beta_{71}\left(\right.$ USIvol $\left._{t-1}\right)$ & $0.5041^{* * *}$ & $0.0680^{* * *}$ & & 0.0924 & 0.0105 & \\
\hline$\beta_{72}$ & $1.0054^{* * *}$ & $0.0230^{* * *}$ & $* * *$ & $0.5603^{* * *}$ & $0.0175^{* * *}$ & $* * *$ \\
\hline$\beta_{73}$ & $0.7234^{* *}$ & $0.0029 *$ & & 0.3816 & 0.0025 & \\
\hline$\beta_{74}$ & $1.3293^{* * *}$ & $0.0018^{* * *}$ & & $0.9277^{* * *}$ & $0.0024^{* * *}$ & \\
\hline Log-likelihood & & -1426.7515 & & & -1702.2431 & \\
\hline Pseudo- $R^{2}$ & & $26.45 \%$ & & & $20.72 \%$ & \\
\hline$\chi^{2}$ stat & & $1022.2^{* * *}$ & & & $881.54^{* * *}$ & \\
\hline
\end{tabular}


Table 20. Multinomial logit regression results for negative and positive daily return coexceedances (computed as the $\mathbf{2 . 5 \%}$ quantile) of 11 European countries industrial market indices, January 2, 2004, to July 11, 2012

\begin{tabular}{|c|c|c|c|c|c|c|}
\hline & \multicolumn{3}{|c|}{ Negative coexceedances } & \multicolumn{3}{|c|}{ Positive coexceedances } \\
\hline & \multicolumn{6}{|c|}{ Model 3} \\
\hline & Coeff. & $\Delta$ prob. & & Coeff. & $\Delta$ prob. & \\
\hline$\beta_{01}($ constant $)$ & $-2.1002^{* * *}$ & $-0.1975^{* * *}$ & & $-1.7249 * * *$ & $-0.2052^{* * *}$ & \\
\hline$\beta_{02}$ & $-3.9807^{* * *}$ & $-0.0653^{* * *}$ & $* * *$ & $-3.7553^{* * *}$ & $-0.0668^{* * *}$ & $* * *$ \\
\hline$\beta_{03}$ & $-5.9298^{* * *}$ & $-0.0121^{* * *}$ & & $-5.2632^{* * *}$ & $-0.0232^{* * *}$ & \\
\hline$\beta_{04}$ & $-5.6142^{* * *}$ & $-0.0172^{* * *}$ & & $-5.2484^{* * *}$ & $-0.0186^{* * *}$ & \\
\hline$\beta_{11}\left(R N_{t-1} / R P_{t-1}\right)$ & $0.1600^{* *}$ & $0.0151^{* *}$ & & $0.1775^{* *}$ & $0.0224^{* *}$ & \\
\hline$\beta_{12}$ & $0.3567^{* * *}$ & $0.0059^{* * *}$ & $* *$ & 0.1383 & 0.0021 & $* *$ \\
\hline$\beta_{13}$ & -0.1313 & -0.0003 & & $0.4453^{* *}$ & $0.0019^{* *}$ & \\
\hline$\beta_{14}$ & 0.1549 & 0.0004 & & -0.2688 & -0.0011 & \\
\hline$\beta_{21}(E A F)$ & $-0.3770^{* * *}$ & $-0.0351^{* * *}$ & & $0.4780^{* * *}$ & $0.0578^{* * *}$ & \\
\hline$\beta_{22}$ & $-0.7481^{* * *}$ & $-0.0122^{* * *}$ & $* * *$ & $0.8532^{* * *}$ & $0.0149^{* * *}$ & $* * *$ \\
\hline$\beta_{23}$ & $-1.4563^{* * *}$ & $-0.0030^{* * *}$ & & $1.1286^{* * *}$ & $0.0048^{* * *}$ & \\
\hline$\beta_{24}$ & $-1.5633^{* * *}$ & $-0.0049^{* * *}$ & & $1.2629 * * *$ & $0.0044^{* * *}$ & \\
\hline$\beta_{31}(E A 10 Y)$ & -0.0143 & -0.0012 & & 0.0423 & 0.0052 & \\
\hline$\beta_{32}$ & -0.1180 & -0.0020 & & 0.0551 & 0.0009 & \\
\hline$\beta_{33}$ & 0.2392 & $0.0005^{*}$ & & 0.0062 & $-8.2801 \times 10^{-6}$ & \\
\hline$\beta_{34}$ & 0.0143 & $5.7152 \times 10^{-5}$ & & 0.1099 & 0.0003 & \\
\hline$\beta_{41}(E U R I B O R 3 M)$ & -0.0509 & -0.0058 & & -0.0048 & -0.0005 & \\
\hline$\beta_{42}$ & $0.2401^{* *}$ & $0.0042^{* * *}$ & $* * *$ & -0.0901 & -0.0017 & \\
\hline$\beta_{43}$ & $0.3555^{* * *}$ & $0.0007^{* * *}$ & & 0.1451 & 0.0006 & \\
\hline$\beta_{44}$ & $0.4246^{* * *}$ & $0.0013^{* * *}$ & & 0.0910 & 0.0003 & \\
\hline$\beta_{51}(E U R / U S D)$ & $-0.2198^{* *}$ & $-0.0212^{* *}$ & & -0.1455 & -0.0195 & \\
\hline$\beta_{52}$ & -0.3252 & -0.0052 & & 0.0491 & 0.0013 & \\
\hline$\beta_{53}$ & -0.0653 & $-7.5771 \times 10^{-5}$ & & 0.4552 & 0.0022 & \\
\hline$\beta_{54}$ & 0.0450 & 0.0002 & & 0.3411 & 0.0013 & \\
\hline Log-likelihood & & 1196.1397 & & & -1391.6114 & \\
\hline Pseudo- $R^{2}$ & & $16.24 \%$ & & & $11.87 \%$ & \\
\hline$\chi^{2}$ stat & & $463.55^{* * *}$ & & & $374.49^{* *}$ & \\
\hline
\end{tabular}


Table 21. Multinomial logit regression results for negative and positive daily return coexceedances (computed as the $2.5 \%$ quantile) of 11 European countries industrial market indices, January 2, 2004, to July 11, 2012

\begin{tabular}{|c|c|c|c|c|c|c|}
\hline & \multicolumn{3}{|c|}{ Negative coexceedances } & \multicolumn{3}{|c|}{ Positive coexceedances } \\
\hline & \multicolumn{6}{|c|}{ Model 4} \\
\hline & Coeff. & $\Delta$ prob. & & Coeff. & $\Delta$ prob. & \\
\hline$\beta_{01}$ (constant) & $-2.1195^{* * *}$ & $-0.2075^{* * *}$ & & $-1.0335^{* * *}$ & $-0.1222^{* * *}$ & \\
\hline$\beta_{02}$ & $-3.1339 * * *$ & $-0.0439 * * *$ & $* * *$ & $-2.4210^{* * *}$ & $-0.0347^{* * *}$ & $* * *$ \\
\hline$\beta_{03}$ & $-3.6033^{* * *}$ & $-0.0013^{* * *}$ & & $-3.4285^{* * *}$ & $-0.0094^{* * *}$ & \\
\hline$\beta_{04}$ & $-3.1162^{* * *}$ & $-0.0014^{* * *}$ & & $-3.2968^{* * *}$ & $-0.0063^{* * *}$ & \\
\hline$\beta_{11}\left(R N_{t-1} / R P_{t-1}\right)$ & $0.1472^{*}$ & $0.0143^{*}$ & & $0.1914^{* *}$ & $0.0237^{* *}$ & \\
\hline$\beta_{12}$ & $0.2725^{* *}$ & $0.0038^{* *}$ & & 0.1371 & 0.0016 & $* *$ \\
\hline$\beta_{13}$ & -0.0641 & $-3.5312 \times 10^{-5}$ & & $0.4357^{* *}$ & $0.0011^{* *}$ & \\
\hline$\beta_{14}$ & 0.0861 & $3.4355 \times 10^{-5}$ & & -0.2903 & -0.0006 & \\
\hline$\beta_{21}(E A F)$ & $-0.3517^{* * *}$ & $-0.0336^{* * *}$ & & $0.5267^{* * *}$ & $0.0628^{* * *}$ & \\
\hline$\beta_{22}$ & $-0.8632^{* * *}$ & $-0.0124^{* * *}$ & $* * *$ & $1.0576^{* * *}$ & $0.0150^{* * *}$ & $* * *$ \\
\hline$\beta_{23}$ & $-2.1661^{* * *}$ & $-0.0008^{* * *}$ & & $1.4887^{* * *}$ & $0.0040^{* * *}$ & \\
\hline$\beta_{24}$ & $-2.5072^{* * *}$ & $-0.0012^{* * *}$ & & $1.6682^{* * *}$ & $0.0032^{* * *}$ & \\
\hline$\beta_{31}(E A 10 Y)$ & -0.0210 & -0.0019 & & 0.0476 & 0.0059 & \\
\hline$\beta_{32}$ & -0.1074 & -0.0016 & $* *$ & 0.0378 & 0.0004 & \\
\hline$\beta_{33}$ & $0.3757^{* *}$ & $0.0001^{* *}$ & & -0.0521 & -0.0001 & \\
\hline$\beta_{34}$ & $0.1954^{*}$ & $0.0001^{*}$ & & 0.0495 & $8.6015 \times 10^{-5}$ & \\
\hline$\beta_{41}(E U R I B O R 3 M)$ & -0.0320 & -0.0035 & & $-0.1097^{*}$ & $-0.0130^{*}$ & \\
\hline$\beta_{42}$ & $0.1880^{*}$ & $0.0029^{*}$ & & $-0.3015^{* * *}$ & $-0.0043^{* *}$ & $* *$ \\
\hline$\beta_{43}$ & 0.1037 & $4.3284 \times 10^{-5}$ & & -0.0915 & -0.0002 & \\
\hline$\beta_{44}$ & $0.2136^{*}$ & $0.0001^{*}$ & & -0.2052 & -0.0003 & \\
\hline$\beta_{51}(E U R / U S D)$ & $-0.2166^{* *}$ & $-0.0210^{*}$ & & -0.1580 & -0.0204 & \\
\hline$\beta_{52}$ & $-0.4106^{*}$ & $-0.0058^{*}$ & & 0.0545 & 0.0011 & \\
\hline$\beta_{53}$ & -0.0845 & $-2.2206 \times 10^{-5}$ & & $0.5669^{*}$ & $0.0017^{*}$ & \\
\hline$\beta_{54}$ & 0.0098 & $2.1536 \times 10^{-5}$ & & 0.3916 & 0.0008 & \\
\hline$\beta_{61}\left(U S R N_{t-1} / U S R P_{t-1}\right)$ & 0.2880 & 0.0277 & & -0.0932 & -0.0136 & \\
\hline$\beta_{62}$ & $1.1834^{* *}$ & 0.0176 & & 0.6486 & 0.0102 & \\
\hline$\beta_{63}$ & -19.5946 & -0.0081 & & -0.1757 & -0.0005 & \\
\hline$\beta_{64}$ & $1.3544^{*}$ & 0.0006 & & $1.4178^{* *}$ & $0.0029 * *$ & \\
\hline$\beta_{71}\left(\right.$ USIvol $\left._{t-1}\right)$ & 0.0181 & 0.0035 & & $-0.5730^{* * *}$ & $-0.0680 * * *$ & \\
\hline$\beta_{72}$ & $-0.7757^{* *}$ & $-0.0117^{* *}$ & $* * *$ & $-1.2352^{* * *}$ & $-0.0176^{* * *}$ & $* * *$ \\
\hline$\beta_{73}$ & $-2.7092^{* * *}$ & $-0.0011^{* * *}$ & & $-1.7912^{* * *}$ & $-0.0049 * * *$ & \\
\hline$\beta_{74}$ & $-3.3429^{* * *}$ & $-0.0017^{* * *}$ & & $-2.0215^{* * *}$ & $-0.0039 * * *$ & \\
\hline Log-likelihood & & -1156.7197 & & & 1362.7701 & \\
\hline Pseudo- $R^{2}$ & & $19 \%$ & & & $13.7 \%$ & \\
\hline$\chi^{2}$ stat & & $542.01^{* * *}$ & & & $431.68^{* * *}$ & \\
\hline
\end{tabular}




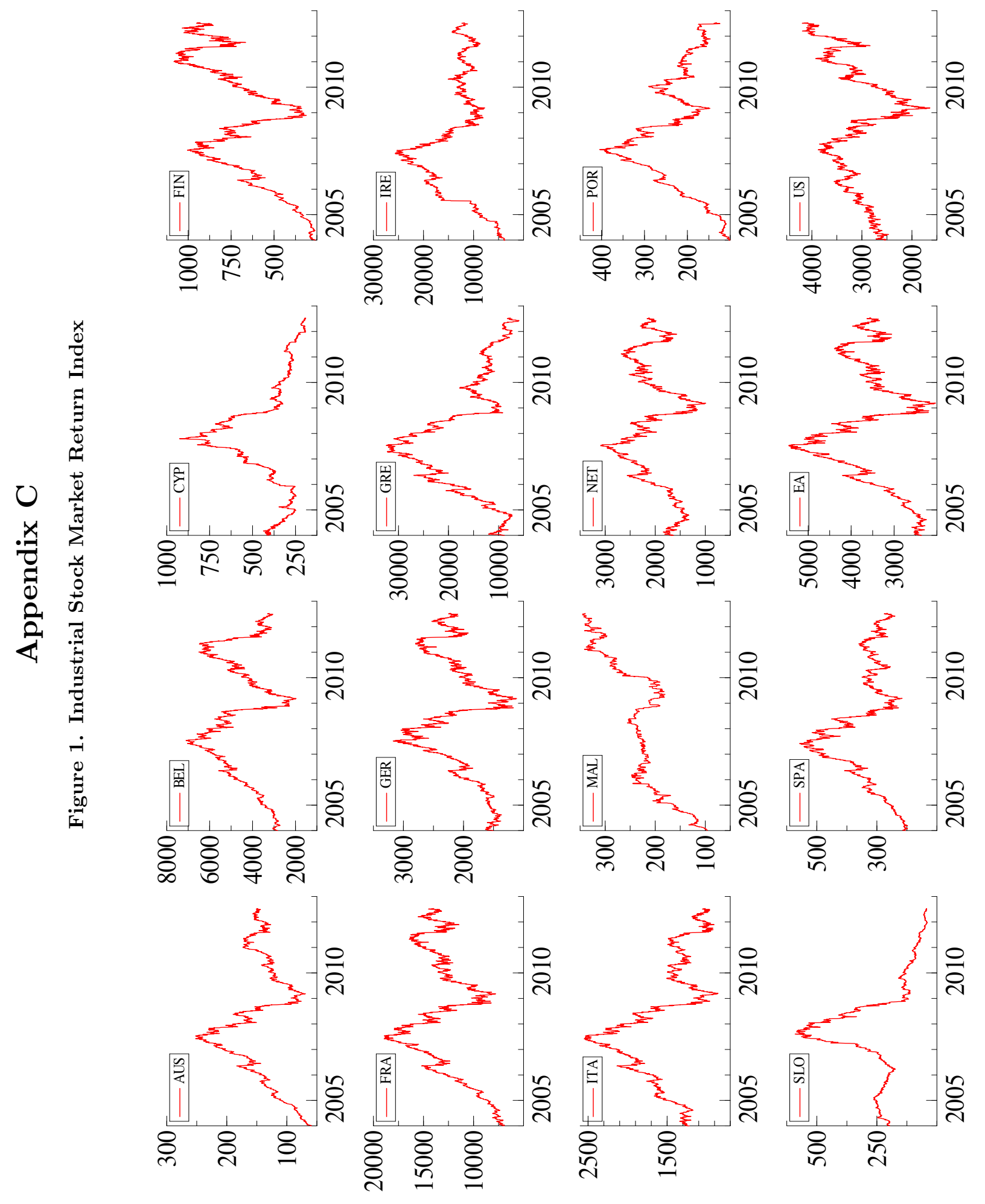



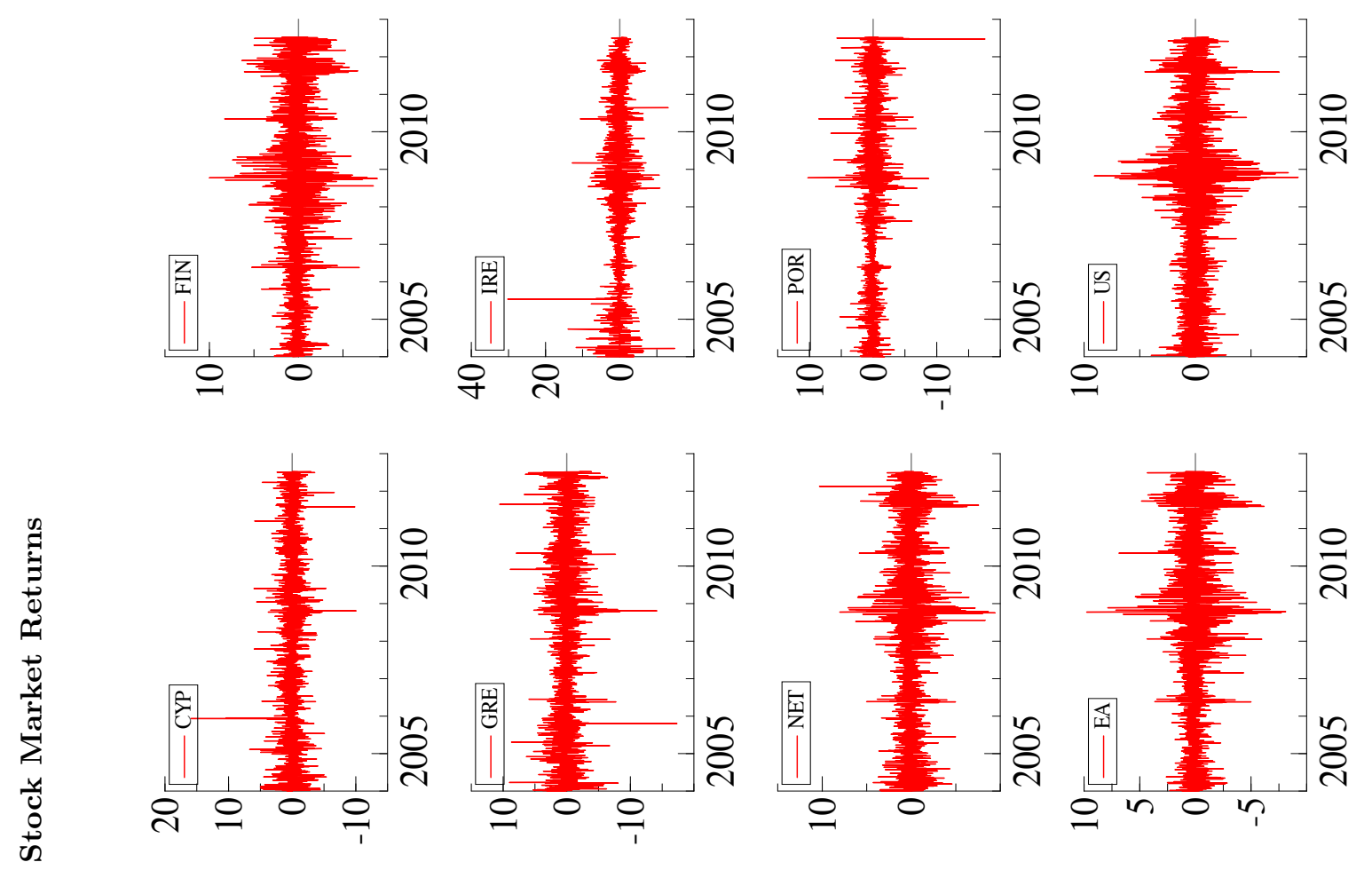

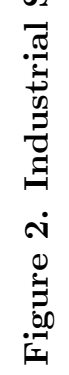
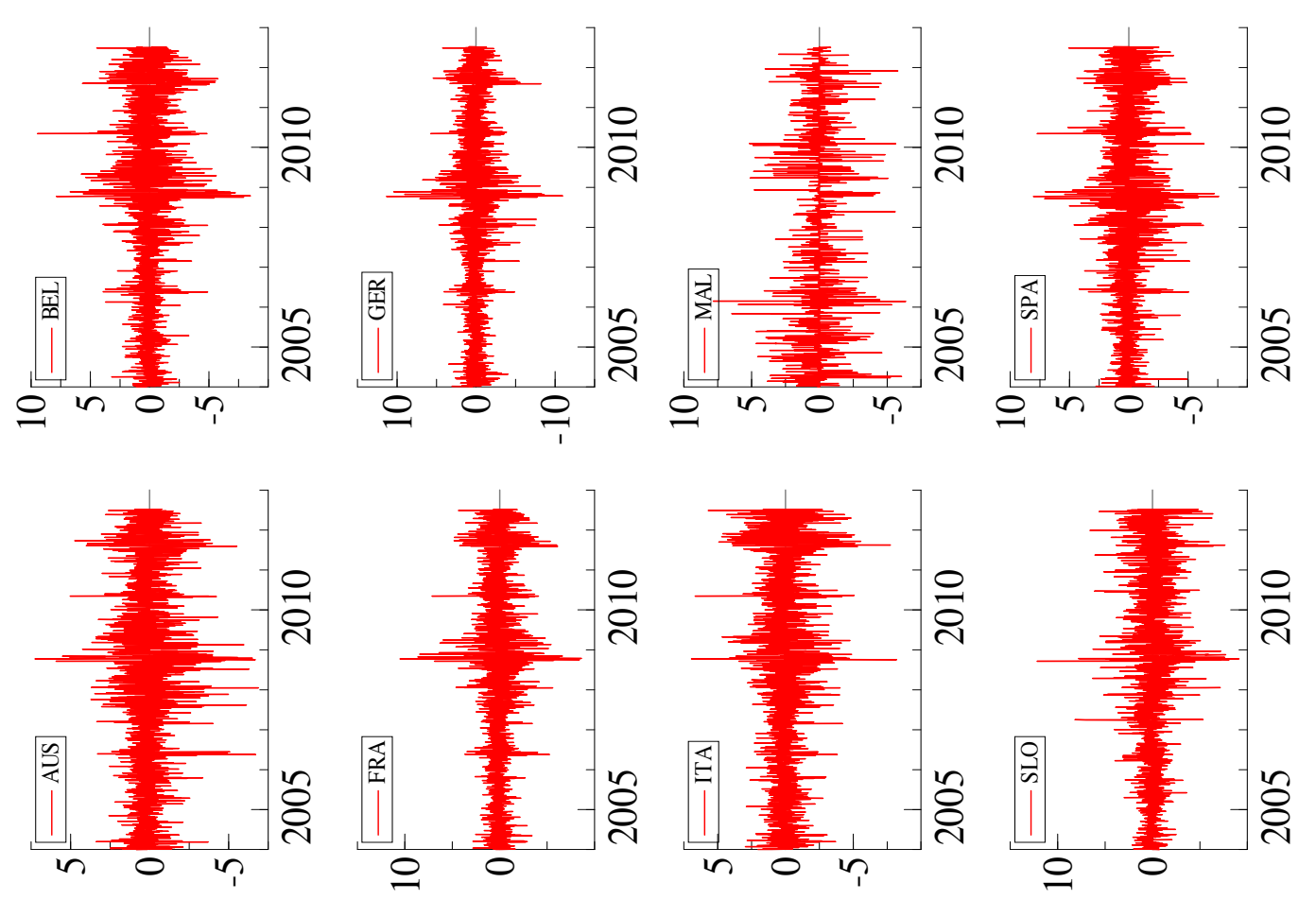


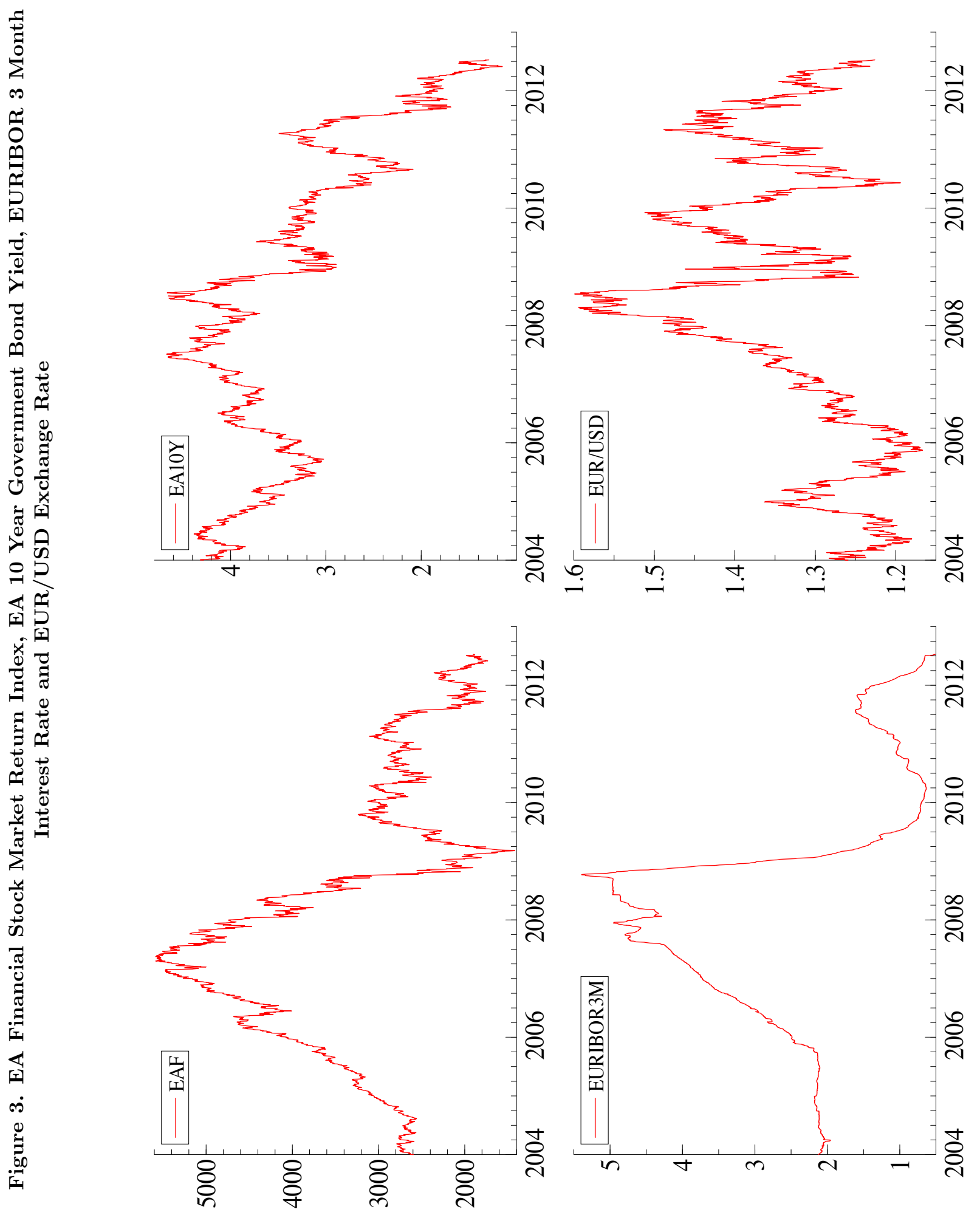




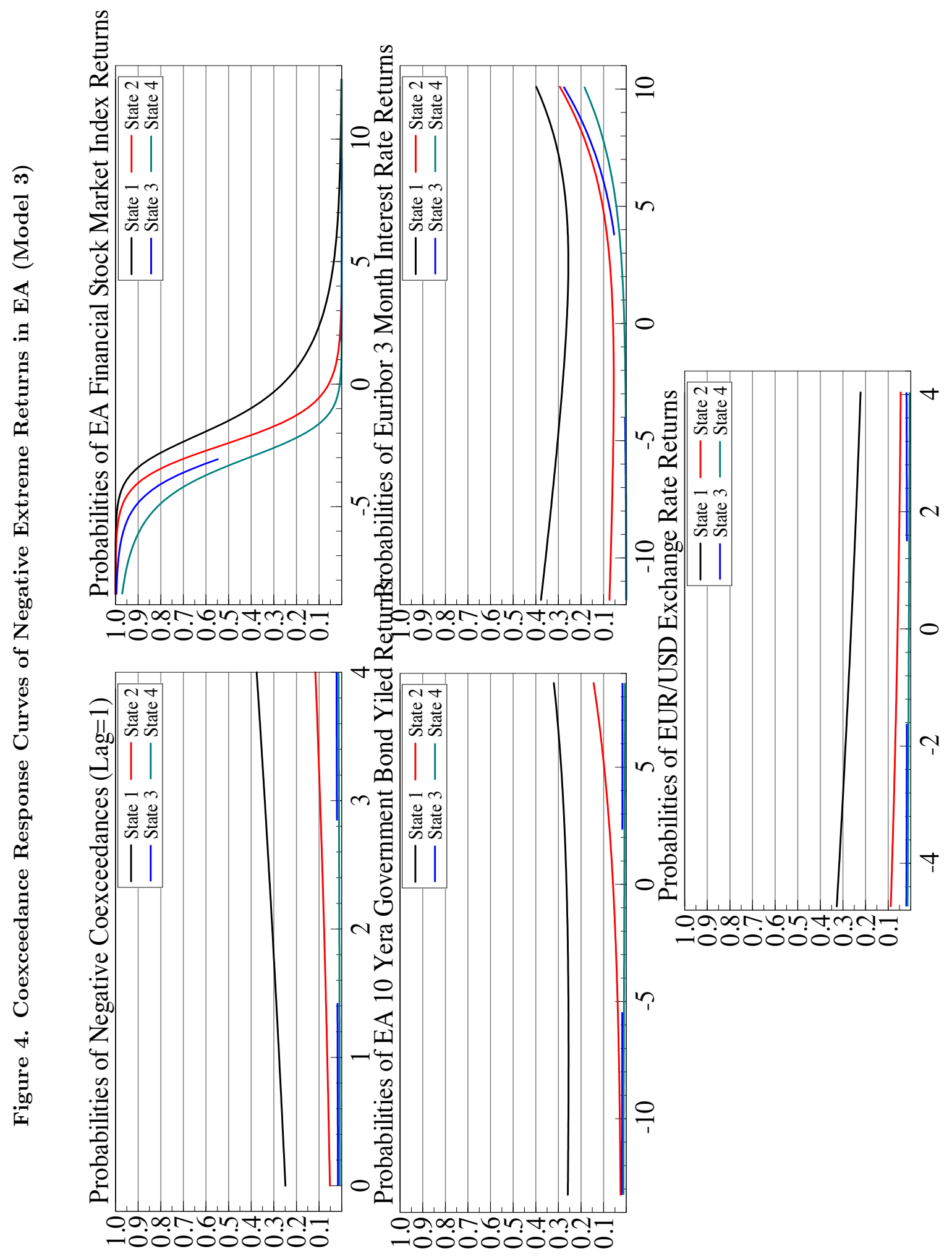




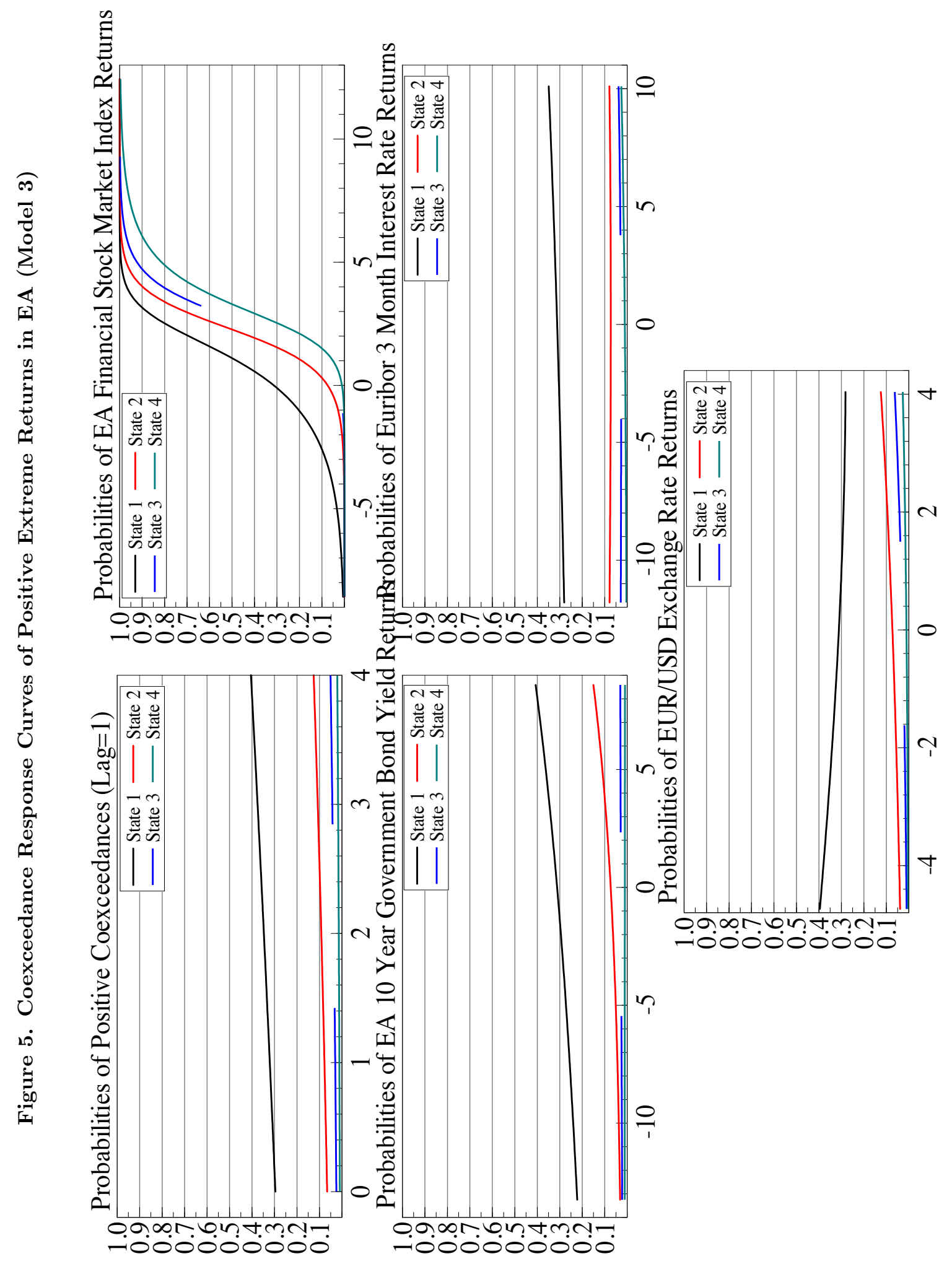




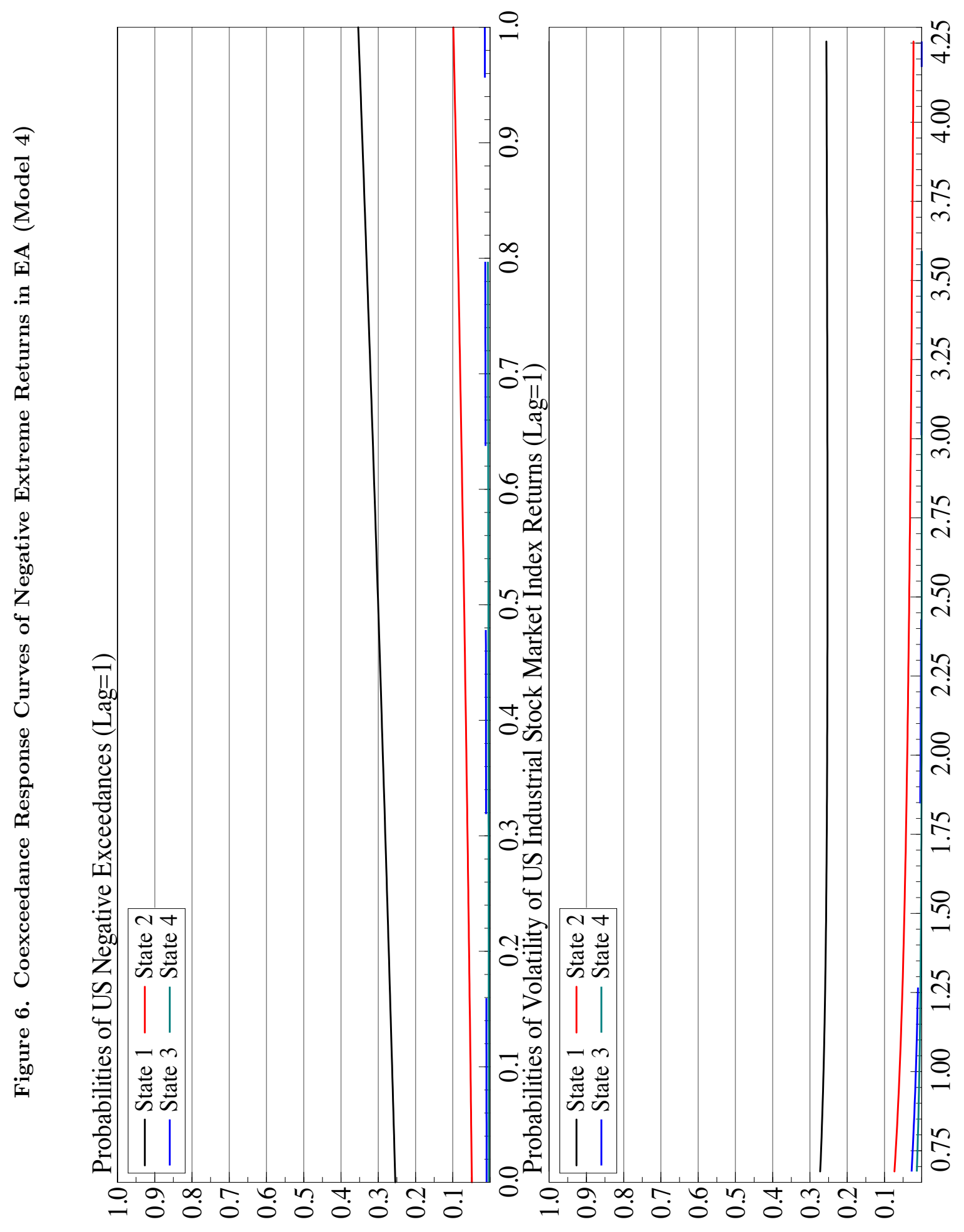




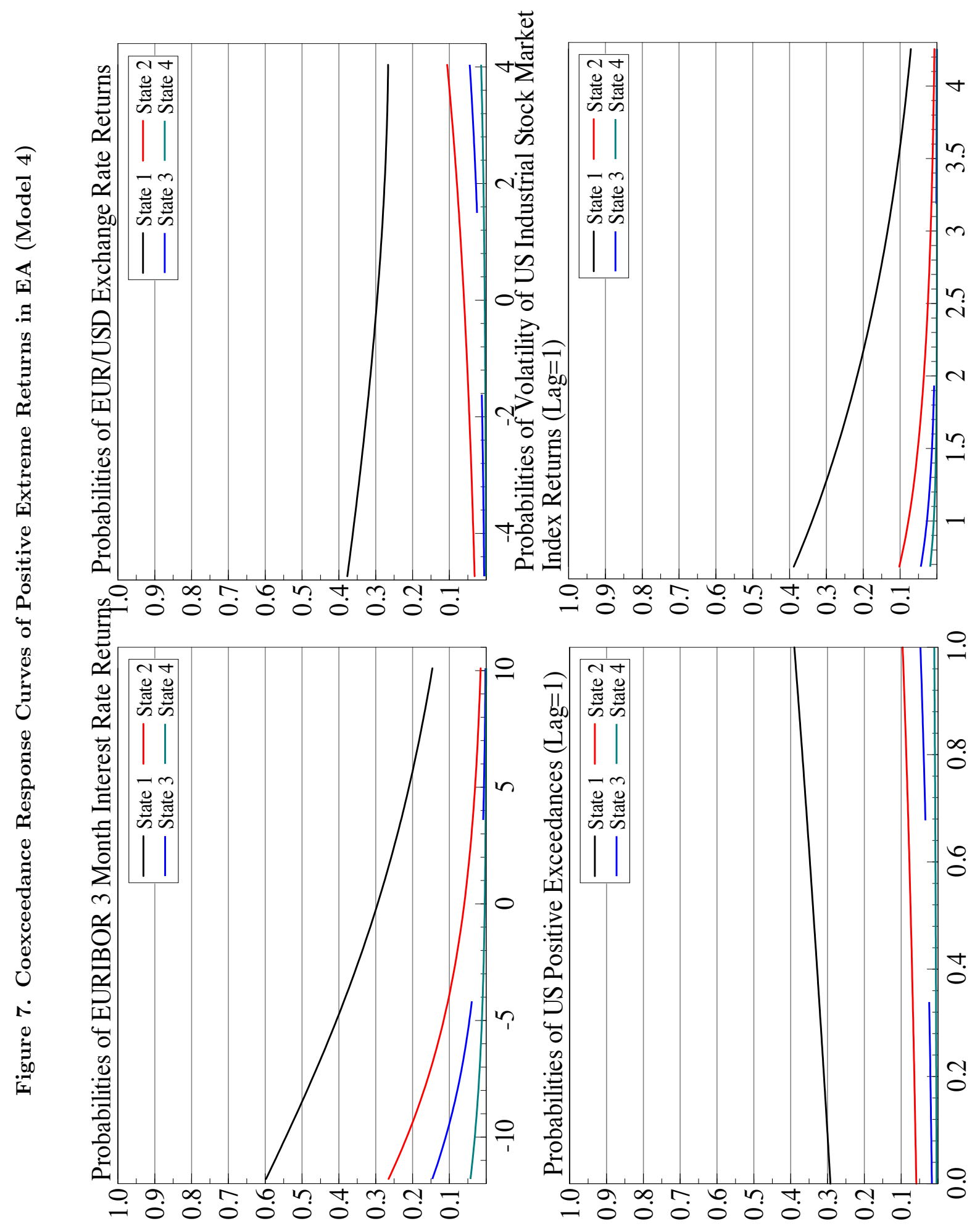




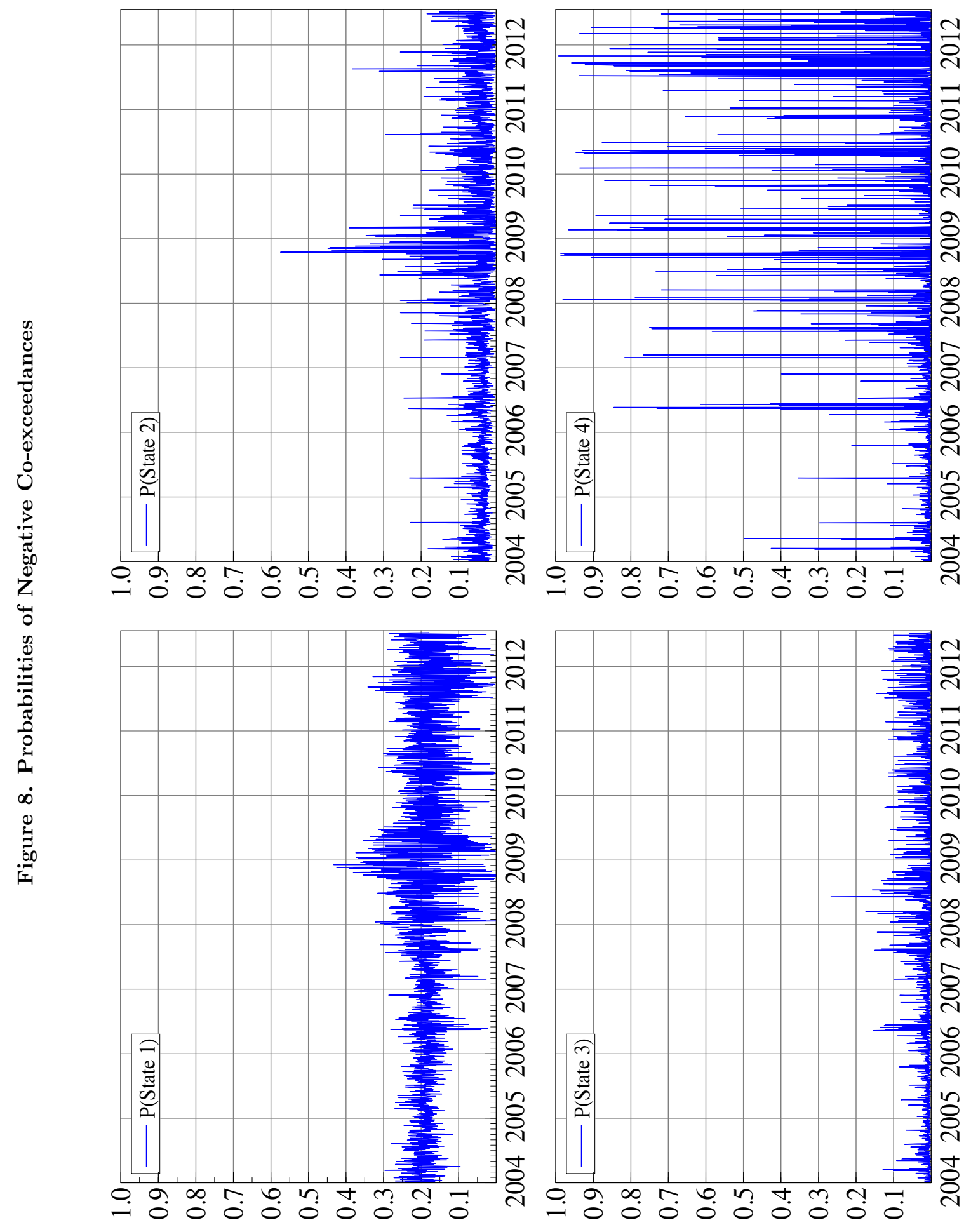




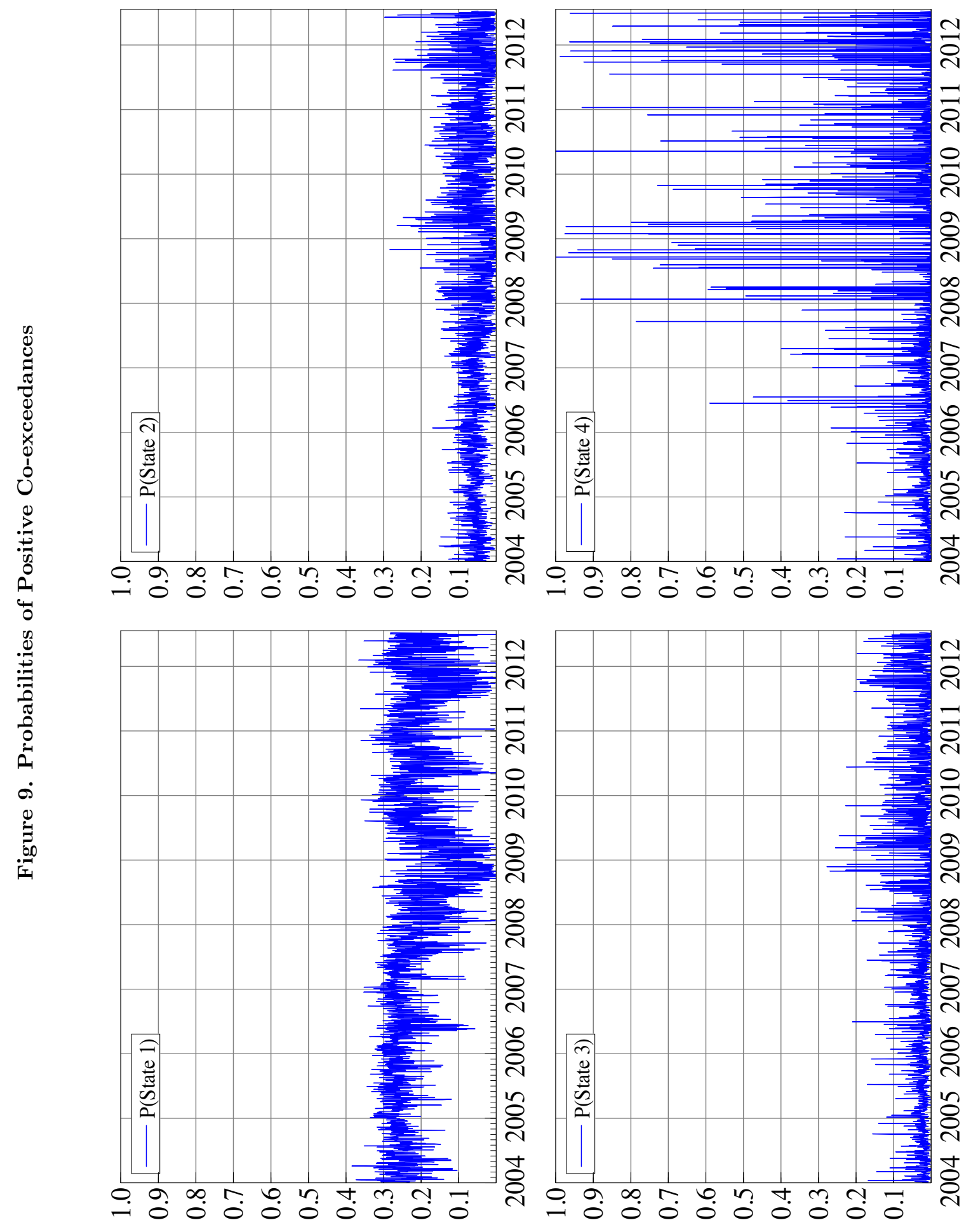

